\title{
Inhaltsübersicht
}

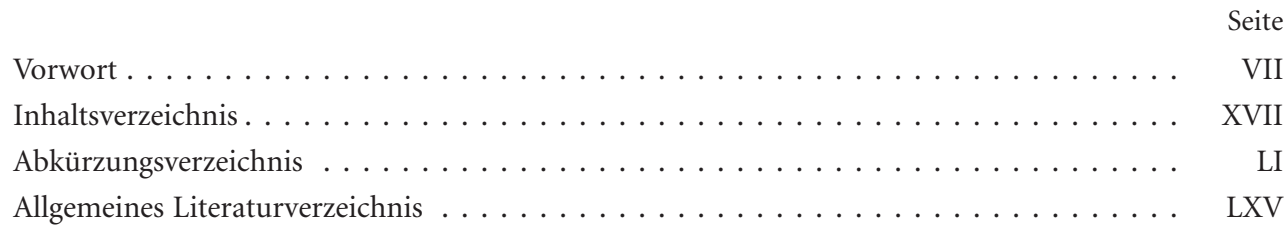

\section{Grundlagen der Steuerrechtsordnung}

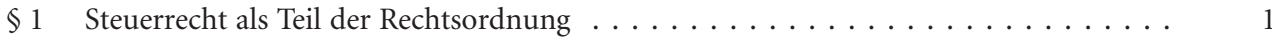

$\$ 2$ Finanzverfassungsrechtliche Grundlagen der Steuerrechtsordnung . . . . . . . . . . 35

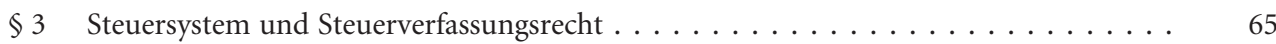

$\$ 4$ Europäisches Steuerrecht . . . . . . . . . . . . . . . . . . . . . . . . . 149

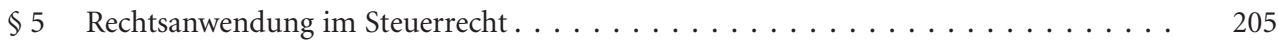

$\$ 6$ Allgemeines Steuerschuldrecht. . . . . . . . . . . . . . . . . . . 249

\section{Besonderes Steuerschuldrecht}

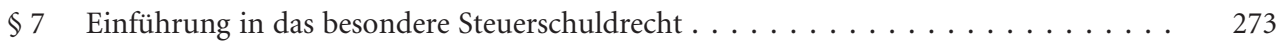

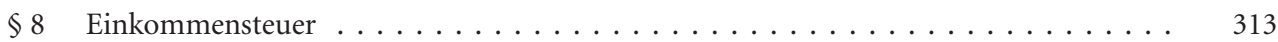

$\$ 9$ Steuerrechtliche Gewinnermittlung (Bilanzsteuerrecht) . . . . . . . . . . . 541

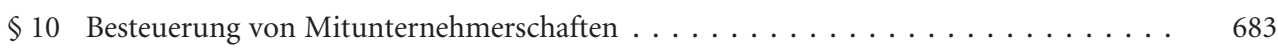

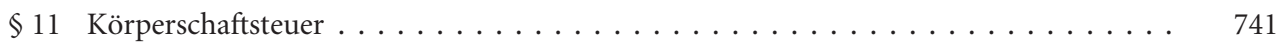

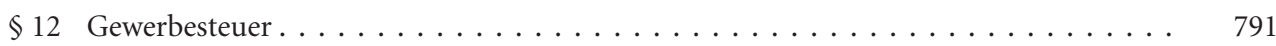

$\$ 13$ Rechtsformabhängige Unternehmensbesteuerung . . . . . . . . . . . . 815

$\$ 14$ Konzern- und Umwandlungssteuerrecht $\ldots \ldots \ldots \ldots \ldots \ldots \ldots \ldots$

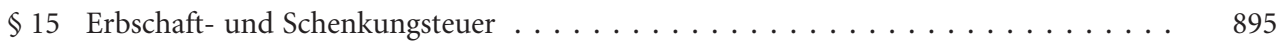

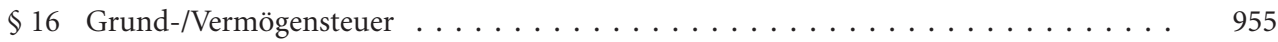

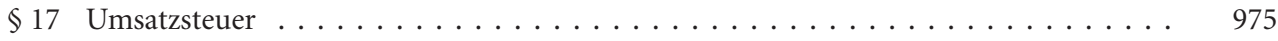

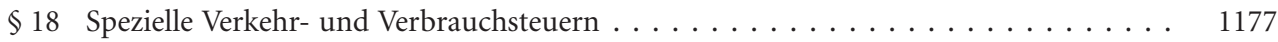

$\$ 19$ Arten und Rechtfertigung von Steuervergünstigungen . . . . . . . . . . . . . . 1235

$\$ 20$ Gemeinnützigkeits- und Spendenrecht $\ldots \ldots \ldots \ldots \ldots \ldots \ldots \ldots \ldots \ldots \ldots$ 
Steuerverfahrens- und Steuerstrafrecht Seite

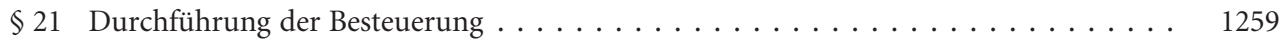

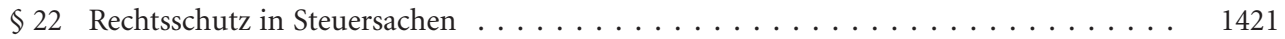

$\$ 23$ Materielles Steuerstraf- und -ordnungswidrigkeitenrecht . . . . . . . . . . . 1513

$\$ 24$ Steuerstraf- und Steuerordnungswidrigkeitenverfahren . . . . . . . . . . . . 1553

Stichwortverzeichnis . . . . . . . . . . . . . . . . . . . . . . . . 1575 


\section{Inhaltsverzeichnis}

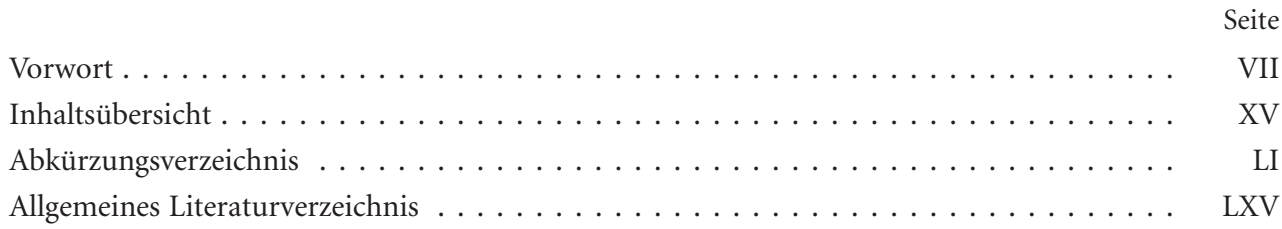

\section{Grundlagen der Steuerrechtsordnung}

\section{$\$ 1$ Steuerrecht als Teil der Rechtsordnung}

1. Gegenstand und Bedeutung des Steuerrechts . . . . . . . . . . . . . . 1

2. Abgrenzung von steuerwissenschaftlichen Nachbardisziplinen . . . . . . . . . 6

3. Steuerrecht als Referenzgebiet des öffentlichen Rechts . . . . . . . . . . . . . . . . . 10

4. Verhältnis des Steuerrechts zu anderen Rechtsgebieten . . . . . . . . . . . . . . 11

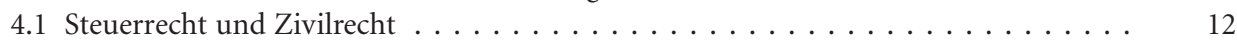

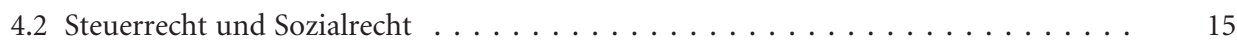

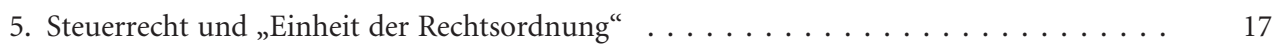

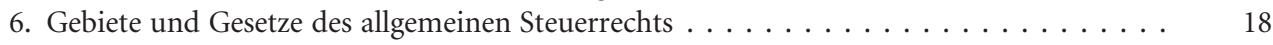

6.1 Das allgemeine Steuerrecht im Überblick . . . . . . . . . . . . . . . . . . 18

6.2 Die Abgabenordnung als Teilkodifikation (Mantelgesetz) des Steuerrechts . . . . . . 18

6.3 Das Bewertungsgesetz als Teilkodifikation (Mantelgesetz) des Steuerrechts . . . . . . 20

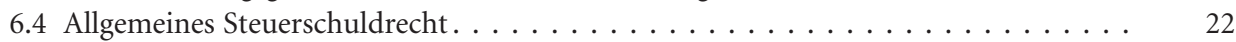

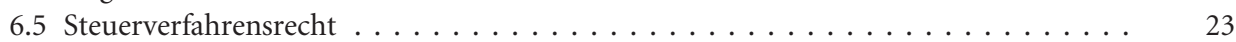

7. Gebiete und Gesetze des besonderen Steuerrechts . . . . . . . . . . . . . . . 25

7.1 Besonderes Steuerschuldrecht und Sondergebiete des Steuerrechts . . . . . . . . . 25

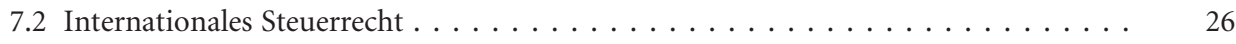

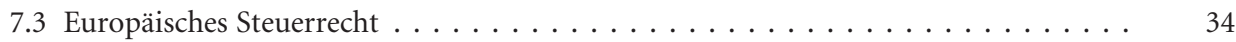

\section{§ 2 Finanzverfassungsrechtliche Grundlagen der Steuerrechtsordnung}

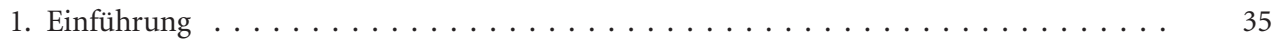

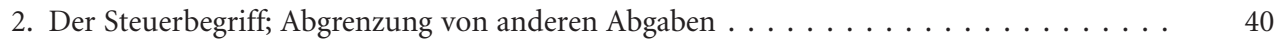

2.1 Verfassungsrechtlicher Inhalt und Bedeutung des Steuerbegriffs . . . . . . . . . . . . 40

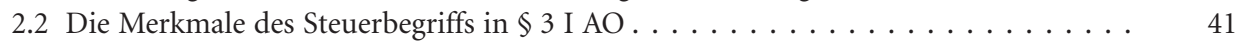

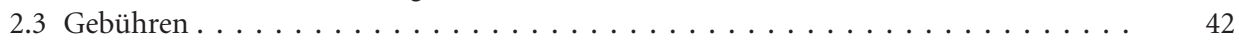

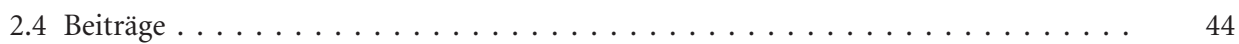

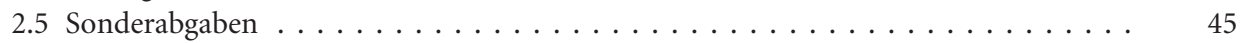

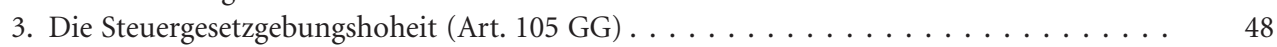

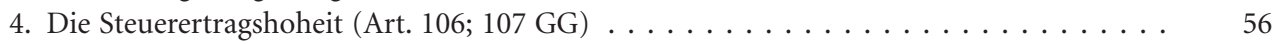

5. Die Steuerverwaltungshoheit (Art. $108 \mathrm{GG}) \ldots \ldots \ldots \ldots \ldots \ldots \ldots \ldots$ 


\section{$\S 3$ Steuersystem und Steuerverfassungsrecht Seite}

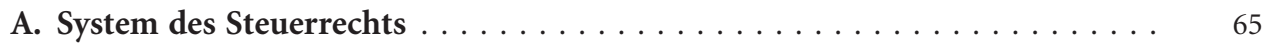

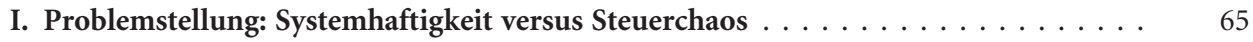

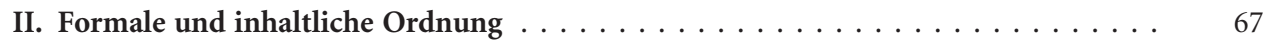

1. Das äußere System . . . . . . . . . . . . . . . . . . . . . . . . . . 67

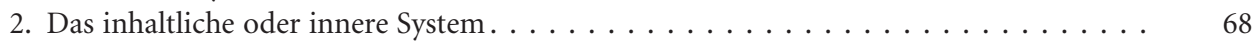

2.1 Prinzipien als Träger des inhaltlichen oder inneren Systems . . . . . . . . . 69

2.2 Die steuergesetzlichen Normgruppen im System . . . . . . . . . . . . . . 71

2.2.1 Drei Normgruppen . . . . . . . . . . . . . . . . . . . . . . 71

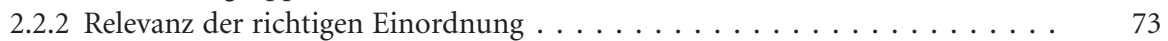

3. Die Effizienz des Systemgedankens . . . . . . . . . . . . . . . . . . . . 74

B. Das Leistungsfähigkeitsprinzip als allgemein anerkanntes Fundamental-

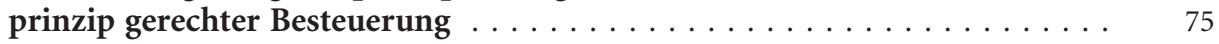

I. Das Leistungsfähigkeitsprinzip als systemtragender Vergleichsmaßstab für

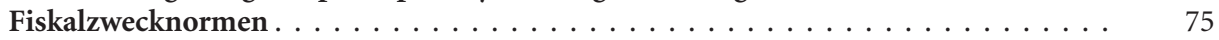

II. Konkretisierungen des Leistungsfähigkeitsprinzips . . . . . . . . . . . . . . . . 79

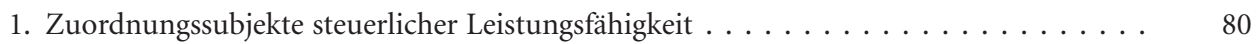

2. Konkretisierung des Leistungsfähigkeitsprinzips im Vielsteuersystem durch Besteuerung von Einkommen, Vermögen und Konsum . . . . . . . . . . . . 80

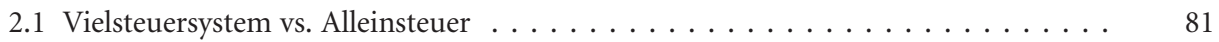

2.2 Leistungsfähigkeitsindikatoren Einkommen, Vermögen, Konsum . . . . . . . . . 82

C. Verfassungsrechtliche Maßstäbe des Steuerrechts . . . . . . . . . . . . . . 91

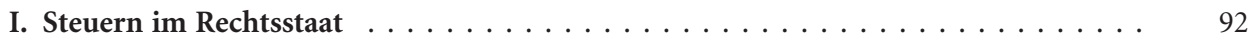

1. Formale und materiale Rechtsstaatlichkeit . . . . . . . . . . . . . . . . . . . . 92

2. Verwirklichung formaler Rechtsstaatlichkeit im Steuerrecht . . . . . . . . . . . . 93

3. Verwirklichung materialer Rechtsstaatlichkeit im Steuerrecht . . . . . . . . . . . . . . . . . 93

4. Steuergerechtigkeit und Verfassungsrecht . . . . . . . . . . . . . . . 95

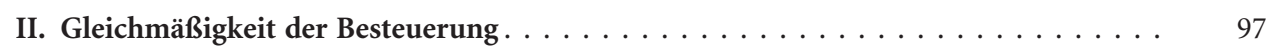

1. Bedeutung und Inhalt des allgemeinen Gleichheitssatzes (Art. 3 I GG) im Steuerrecht . 97

2. Gebot der Rechtsanwendungsgleichheit . . . . . . . . . . . . . . . . 98

3. Gebot der Rechtssetzungsgleichheit . . . . . . . . . . . . . . . . . . 100

4. Steuerrechtsspezifische Konkretisierungen des Allgemeinen Gleichheitssatzes . . . . . . 102

5. Rechtfertigung von Ungleichbehandlungen und Kontrolldichte . . . . . . . . . . . . . . . . 103

5.1 Willkürverbot oder Gebot verhältnismäßiger Gleichheit? . . . . . . . . . . . . . . . 103

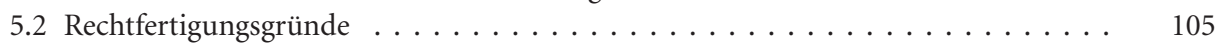

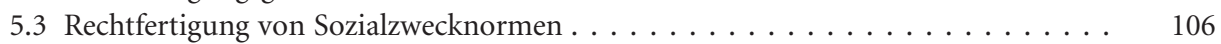

5.4 Rechtfertigung von Vereinfachungszwecknormen . . . . . . . . . . . . . 108

6. Gleichmäßige Besteuerung und Steuerföderalismus . . . . . . . . . . . . . . 110

III. Der verfassungsrechtliche Schutz des Existenzminimums . . . . . . . . . . . . . 111

IV. Leistungsfähigkeitsgerechte Besteuerung der Familie . . . . . . . . . . . . . . 112 


\section{Freiheitsrechtliche Schranken der Besteuerung und Übermaßver}

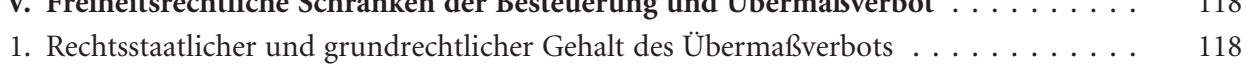

1.1 Verhältnismäßigkeit staatlichen Handelns . . . . . . . . . . . . . . . . . . . 118

1.2 Relative Wirkungslosigkeit des freiheitsrechtlichen Übermaßverbots gegenüber dem Steuereingriff . . . . . . . . . . . . . . . . . . . . . . . . . . . . . . . . . . . . . . . . . . .

1.3 Das Verbot der Erdrosselungssteuer . . . . . . . . . . . . . . . . . . . . . . . . . . . . . . . . . . . . . . . . . .

2. Art. 2 I GG als allgemeine Schranke der Besteuerung . . . . . . . . . . . . . . . . . . . . 121

3. Bedeutung von Art. 4 GG für das Steuerrecht . . . . . . . . . . . . . . . . . . . . . . . . . . . . . . . . . . . . . .

4. Steuern als Eingriff in die Berufsfreiheit (Art. 12 GG) . . . . . . . . . . . . . . . . 122

5. Das Prinzip eigentumsschonender Besteuerung (Art. 14 GG) . . . . . . . . . . . 123

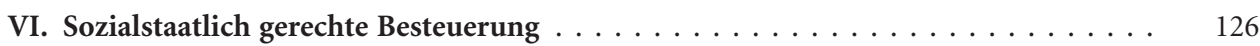

VII. Formale Rechtsstaatlichkeit der Besteuerung . . . . . . . . . . . . . . . . . . . . . . 127

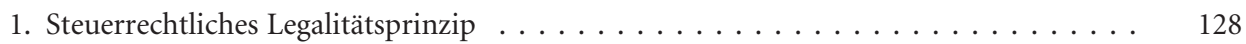

1.1 Inhalt und Bedeutung des steuerrechtlichen Legalitätsprinzips . . . . . . . . . . . 128

1.2 Rechtsgrundlagen des steuerrechtlichen Legalitätsprinzips . . . . . . . . . . . . . . . . . . . . . . . . . . .

1.3 Konkretisierungen des steuerrechtlichen Legalitätsprinzips . . . . . . . . . . . . . . . . . . 129

1.4 Gesetzmäßigkeit des Verwaltungshandelns . . . . . . . . . . . . . . . . . . . . . . . . . . 131

2. Gebote der Bestimmtheit und Normenklarheit . . . . . . . . . . . . . . . . . . . . . . . 133

3. Rechtssicherheit durch Vertrauensschutz . . . . . . . . . . . . . . . . . . . . . . . . . . . . . . . . .

3.1 Prinzipielles Verbot rückwirkender Steuergesetze . . . . . . . . . . . . . . . . . . . . . . . . . . . . . . . . . . .

3.1.1 Verfassungsrechtliche Grundlagen . . . . . . . . . . . . . . . . . . . . . 137

3.1.2 Unterscheidung zwischen echter und unechter Rückwirkung . . . . . . . . . . . 138

3.1.3 Rechtfertigung rückwirkender Steuergesetze . . . . . . . . . . . . . . . . . . . . . . . . . 142

3.2 Rückwirkende Gesetzesanwendung . . . . . . . . . . . . . . . . . . . . . . 146

\section{$\$ 4$ Europäisches Steuerrecht}

A. Rechtsnormen des Europäischen Steuerrechts . . . . . . . . . . . . . . 149

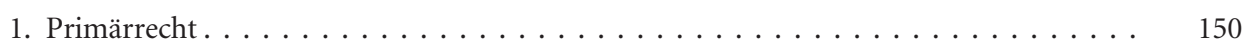

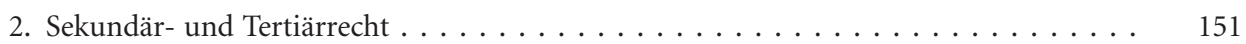

3. Verhältnis von Primär- und Sekundärrecht . . . . . . . . . . . . . . . . . . 152

4. Keine Rechtsnormen . . . . . . . . . . . . . . . . . . . . . . 154

4.1 Rechtlich unverbindliche Erklärungen von EU-Organen . . . . . . . . . . . . 154

4.2 Entscheidungen der europäischen Gerichte . . . . . . . . . . . . . 156

B. Einwirkung des Europarechts auf nationale Steuerrechtsnormen . . . . . 157

1. Anwendungsvorrang der Grundfreiheiten . . . . . . . . . . . . . . . . . . . . . . . . . . . . 157

2. Unionsrecht und harmonisiertes Steuerrecht . . . . . . . . . . . . . . . 160

3. Durchführungsverbot und Rückforderungsgebot bei steuerlichen Beihilfen . . . . . . . 164

4. Durchsetzung des Unionsrechts im Wege nationalen Steuerverfahrensrechts . . . . . . 167

5. Verhältnis zu verfassungsrechtlichen Wertungen . . . . . . . . . . . . 170 
C. Rechtsgrundlagen und Stand steuerrechtlicher Harmonisierung . . . . . . 173

1. Harmonisierung der indirekten Steuern . . . . . . . . . . . . . . . . . . 173

2. Harmonisierung der direkten Steuern . . . . . . . . . . . . . . . . . . 174

D. Verbote steuerlicher Beschränkung von EU-Grundfreiheiten . . . . . . . . . 178

1. Anwendungsbereich . . . . . . . . . . . . . . . . . . . . . . . . . 179

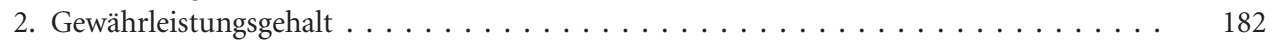

3. Rechtfertigung von Grundfreiheitsverstößen . . . . . . . . . . . . . . . . . . . . 189

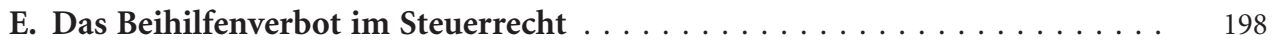

\section{$\S 5$ Rechtsanwendung im Steuerrecht}

A. Rechtsnormen des Steuerrechts . . . . . . . . . . . . . . . 205

1. Parlamentsgesetze . . . . . . . . . . . . . . . . . . . . . . . 205

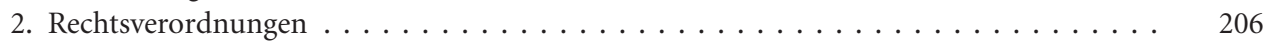

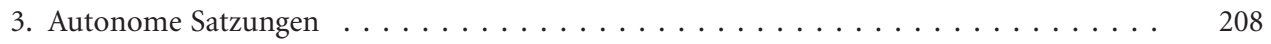

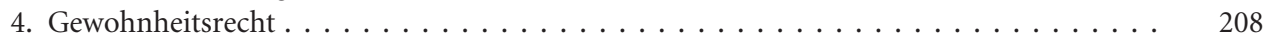

5. Supranationales europäisches Recht . . . . . . . . . . . . . . . . . . . 209

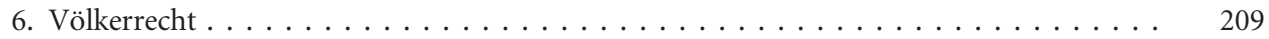

7. Keine Rechtsnormen . . . . . . . . . . . . . . . . . . . . . . 210

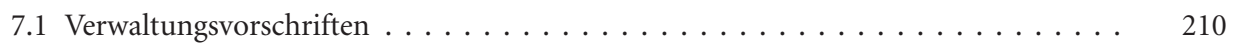

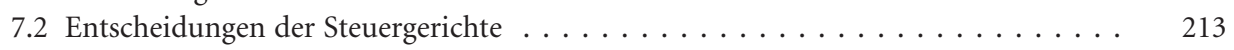

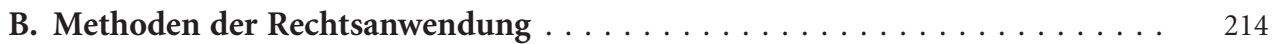

1. Struktur von Rechtsnormen, Syllogismus der Rechtsfolgebestimmung und Primat teleologischer Auslegung . . . . . . . . . . . . . . . . . . . . . 215

2. Der Kanon der traditionellen Auslegungsmethoden. . . . . . . . . . . . . . . . . . 219

3. Wirtschaftliche Interpretation der Steuergesetze (wirtschaftliche Betrachtungsweise) . . . 224

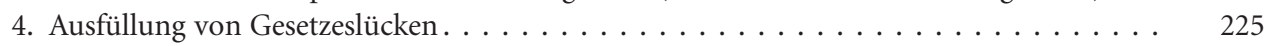

5. Verfassungskonforme Rechtsanwendung . . . . . . . . . . . . . . . . 231

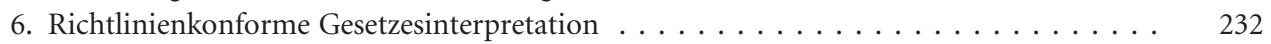

C. Steuergesetzliche Vorschriften zur wirtschaftlichen Betrachtungsweise . . . 233

1. Wirtschaftliche Betrachtungsweise bei Divergenz zwischen wirtschaftlichem Verhalten und juristischem Zustand $(\$ 41 \mathrm{AO}) \ldots \ldots \ldots \ldots \ldots$

2. Wirtschaftliche Betrachtungsweise bei gesetzwidrigem oder sittenwidrigem Verhalten

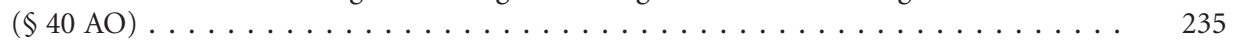

3. Wirtschaftliche Betrachtungsweise bei Gestaltungsmissbrauch $(\$ 42$ AO) . . . . . . . . . . 236

3.1 Zweck und Anwendungsbereich des $\$ 42 \mathrm{AO} \ldots \ldots \ldots \ldots \ldots$

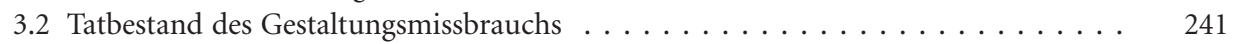

3.3 Rechtsfolge . . . . . . . . . . . . . . . . . . . . . . . . . . . 244 
Seite

4. Wirtschaftliche Zurechnung statt Maßgeblichkeit der zivilrechtlichen Berechtigung

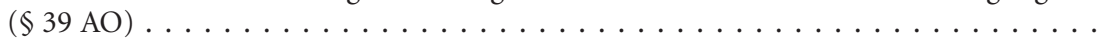

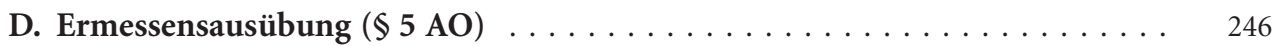

\section{$\$ 6$ Allgemeines Steuerschuldrecht}

1. Inhalt des Steuerschuldverhältnisses . . . . . . . . . . . . . . . . . . . 249

1.1 Steuerschuldverhältnis als materiell-rechtlicher Teil des Steuerrechtsverhältnisses . . 249

1.2 Kanon der Ansprüche aus dem Steuerschuldverhältnis . . . . . . . . . . . . . . 249

2. Entstehung von Ansprüchen aus dem Steuerschuldverhältnis . . . . . . . . . . . . . 250

3. Gläubiger- und Schuldnerwechsel, Verpfändung, Pfändung . . . . . . . . . . . . . . . . . 251

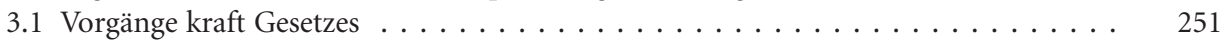

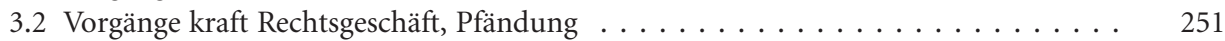

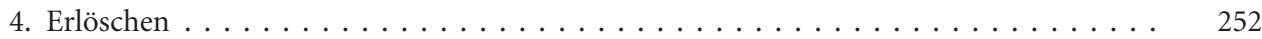

5. Steueranspruch und Steuerschuld . . . . . . . . . . . . . . . . . . 252

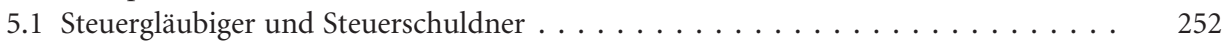

5.2 Entstehung des Steueranspruchs . . . . . . . . . . . . . . . . 253

5.3 Der Entstehungstatbestand des Steueranspruchs (Steuertatbestand) . . . . . . . 255

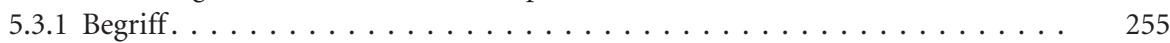

5.3.2 Das Steuersubjekt und die Steuerrechtsfähigkeit . . . . . . . . . . . . . . . 256

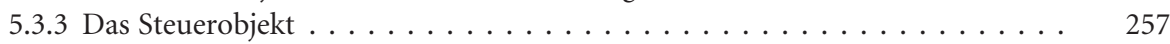

5.3 .4 Die Zurechnung . . . . . . . . . . . . . . . . . 258

5.3.5 Die abstrakten Merkmale des inländischen Steuerschuldverhältnisses . . . . . 258

5.3.6 Die Steuerbemessungsgrundlage . . . . . . . . . . . . . . . . 258

5.3.7 Der Steuersatz. . . . . . . . . . . . . . . . . . . . . . . . . . . 259

5.3 .8 Die Steuervergünstigungen . . . . . . . . . . . . . . . . . 259

5.4 Konkurrenz der Steuertatbestände oder Steueransprüche . . . . . . . . . 261

6. Die Gesamtschuldnerschaft . . . . . . . . . . . . . . . . . . . . . . . 262

7. Der Haftungsanspruch . . . . . . . . . . . . . . . . . . . . . . . 263

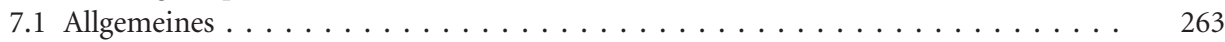

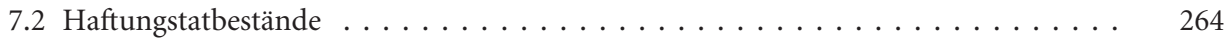

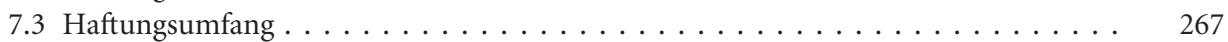

7.4 Akzessorietät der Haftung . . . . . . . . . . . . . . . . . . . . . 267

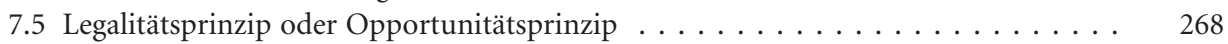

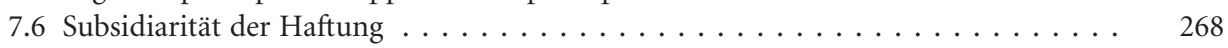

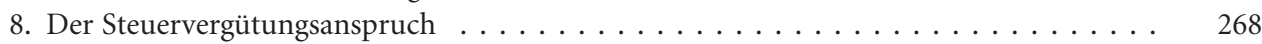

9. Der Steuererstattungsanspruch . . . . . . . . . . . . . . . . . . 270 


\section{Besonderes Steuerschuldrecht}

\section{$\$ 7$ Einführung in das besondere Steuerschuldrecht Seite}

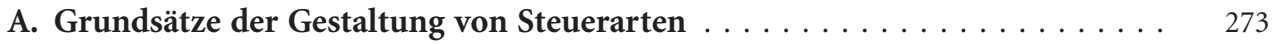

B. Steueraufkommen, Steuerquote und Steuerarten in Deutschland . . . . . . 278

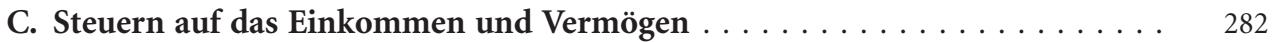

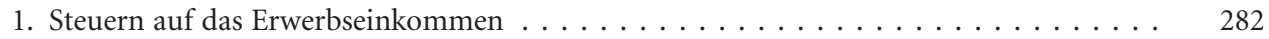

2. Besteuerung des Vermögenstransfers durch die Erbschaft- und Schenkungsteuer . . . . . 285

3. Besteuerung des Vermögensbestandes durch Substanzsteuern . . . . . . . . . . . . . . 287

4. Reform der Besteuerung von Einkommen . . . . . . . . . . . . . . . . 288

D. Steuern auf die Verwendung von Einkommen und Vermögen . . . . . . . . 302

E. Besondere Sozialzwecksteuern . . . . . . . . . . . . . . . . . . . . . 304

1. Zölle und Abschöpfungen . . . . . . . . . . . . . . . . . . . . . . . . 304

2. Umweltsteuern . . . . . . . . . . . . . . . . . . . . . . . . . . . . . . . 304

\section{$\$ 8$ Einkommensteuer}

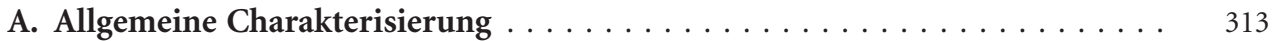

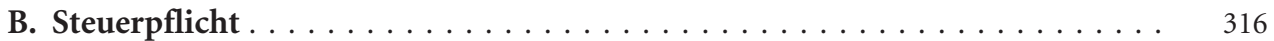

1. Natürliche Personen als Steuersubjekte . . . . . . . . . . . . . . . 316

2. Internationale Abgrenzung der Steuerpflicht durch die unbeschränkte und beschränkte

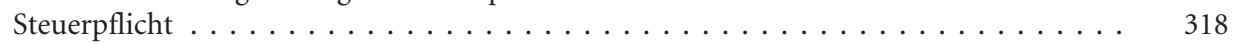

C. Objekt und Bemessungsgrundlage der Einkommensteuer . . . . . . . . . 322

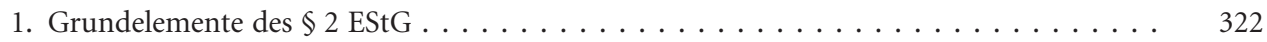

1.1 Bedeutung des $\$ 2$ EStG für den Einkommensteuertatbestand . . . . . . . . . . 322

1.2 Disponibles Einkommen als Maßstab objektiver und subjektiver Leistungsfähigkeit. $\quad 323$

1.3 Periodizität der Einkommensteuer und Jahressteuerprinzip (\$2 VII EStG) . . . . . 324

1.4 Periodischer Entstehungszeitpunkt der Einkommensteuer . . . . . . . . . . . . . 325

2. Das Einkommensteuerobjekt: Summe der Einkünfte $(\$ 2$ I-III EStG) . . . . . . . . . . 325

2.1 Zur rechtlichen Bestimmung des Steuerguts „Einkommen“ . . . . . . . . . . . 325

2.1.1 Das Einkommen als zentraler Begriff des öffentlichen Schuldrechts . . . . . . 325

2.1.2 Reinvermögenszugangs-, Quellen- und Markteinkommenstheorie . . . . . . . 326

2.1.3 Pragmatische Legaldefinition des Einkommens durch den Einkünftekatalog. . 327

2.2 Bestimmung der Einkünfte nach dem objektiven Nettoprinzip . . . . . . . . . . . 328

2.3 Ermittlung der Einkünfte nach dem Nominalwertprinzip . . . . . . . . . . . . . 330

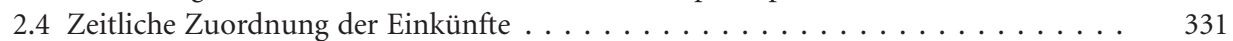




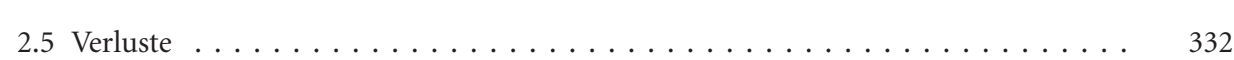

2.5.1 Verlustausgleich und Verlustabzug (Verlustrücktrag/-vortrag) . . . . . . . . . . . 332

2.5.2 Beschränkungen des Verlustausgleichs und Verlustabzugs . . . . . . . . . . 334

3. Die Bemessungsgrundlage der Einkommensteuer: das zu versteuernde Einkommen i.S.d. $\$ 2$ V EStG . . . . . . . . . . . . . . . . . . . . . . . 339

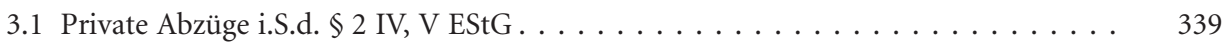

3.1.1 Das subjektive Nettoprinzip als Grundlage der Berücksichtigung existenznotwendiger Privatausgaben und die Lehre vom indisponiblen Einkommen . 339

3.1.2 Berücksichtigung des existenznotwendigen Lebensbedarfs . . . . . . . . . . . . 343

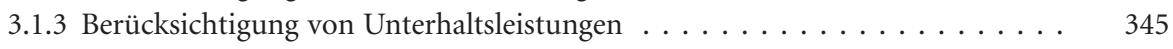

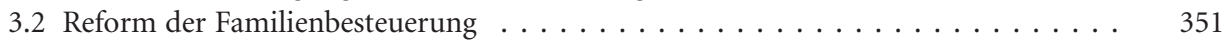

4. Tatbestandstechnischer Aufbau des zu versteuernden Einkommens . . . . . . . . . . 353

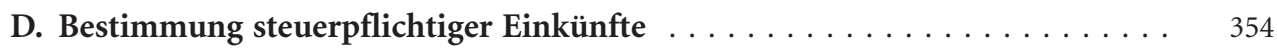

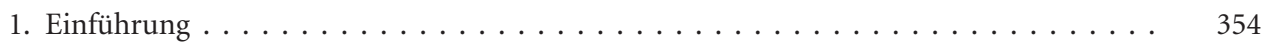

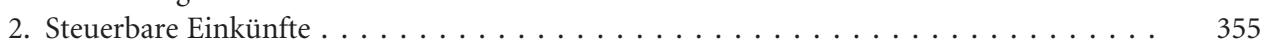

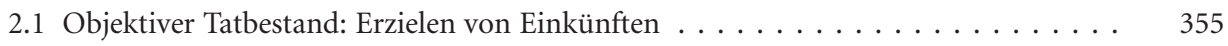

2.2 Subjektiver Tatbestand: Einkünfteerzielungsabsicht $\ldots \ldots \ldots \ldots \ldots \ldots \ldots$

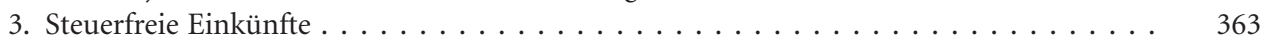

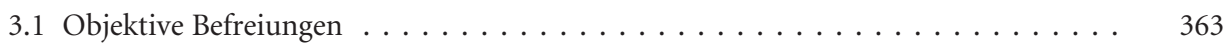

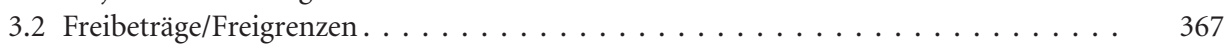

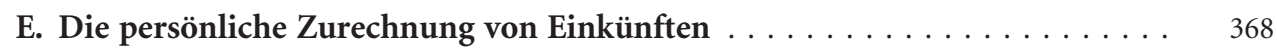

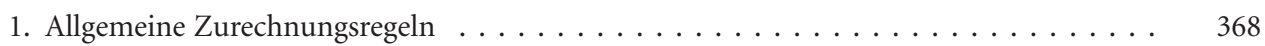

2. Konkretisierung der Zurechnungsregeln bei einzelnen Einkunftsarten . . . . . . . . . . . 369

3. Zurechnung von Einkünften unter Familienangehörigen . . . . . . . . . . . . . 372

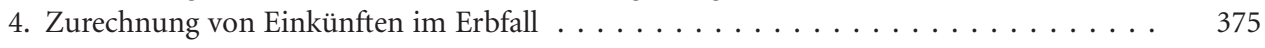

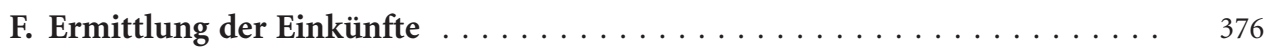

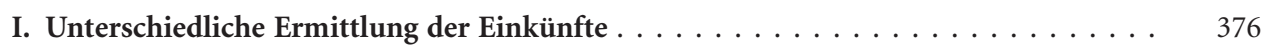

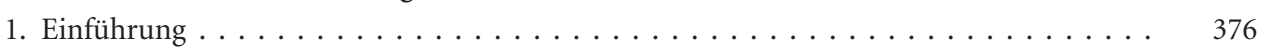

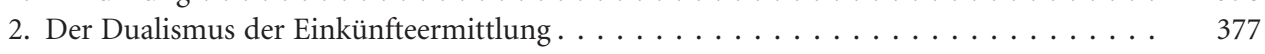

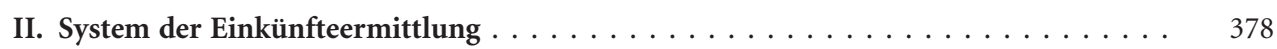

1. Typen der Einkünfteermittlung $\ldots \ldots \ldots \ldots \ldots \ldots \ldots \ldots \ldots \ldots \ldots$

1.1 Ermittlung der Einkünfte durch Bilanzierung. . . . . . . . . . . . . 379

1.2 Überschussrechnungen nach dem Zufluss- und dem Abflussprinzip

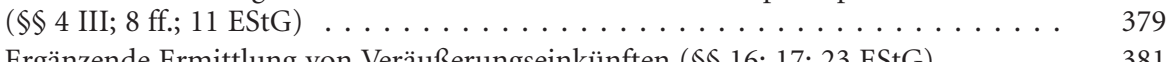

1.3 Ergänzende Ermittlung von Veräußerungseinkünften $(\$ \$ 16 ; 17 ; 23 \mathrm{EStG}) \ldots \ldots . . \quad 381$

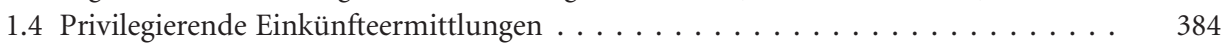

1.5 Personelle Zuordnung der Gewinnermittlungsarten . . . . . . . . . . . 385

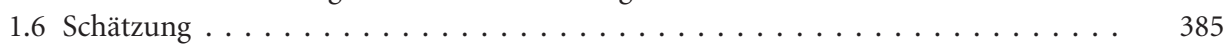

2. Grundbegriffe der Einkünfteermittlung $\ldots \ldots \ldots \ldots \ldots \ldots \ldots \ldots \ldots \ldots$

2.1 Das terminologische System der Erwerbsbezüge und Erwerbsaufwendungen . . . . . 386

2.1.1 Die Abgrenzung der Erwerbssphäre zur Privatsphäre . . . . . . . . . . . . . . 386

2.1.1.1 Finalität und Kausalität des Handelns . . . . . . . . . . . . . 386 
Seite

2.1.1.2 Bestimmung der Erwerbsbezüge und Erwerbsaufwendungen durch das Veranlassungsprinzip . . . . . . . . . . . . .

2.1.1.3 Subjektiv-finale und objektive Ursachen . . . . . . . . . . . . .

2.1.1.4 Zusammentreffen mehrerer Ursachen . . . . . . . . . . . . . . . . .

2.1.2 Die persönliche Zurechnung von Erwerbsbezügen, Erwerbsaufwendungen und von sog. Drittaufwand . . . . . . . . . . . . . . . . . . 392

2.1.3 Die zeitliche Zuordnung von Erwerbsbezügen und Erwerbsaufwendungen . 395

2.1.4 Zusammenfassung. . . . . . . . . . . . . . . . . . . 395

2.2 Abgrenzung der Betriebsausgaben/Werbungskosten zu den Privatausgaben . . . . . 396

2.2.1 Inhaltsgleiche Interpretation des Betriebsausgaben- und des Werbungs-

kostenbegriffs nach dem Veranlassungsprinzip . . . . . . . . . . . . . . . . . . 397

2.2.2 Gemischt veranlasste Aufwendungen . . . . . . . . . . . . . . . 401

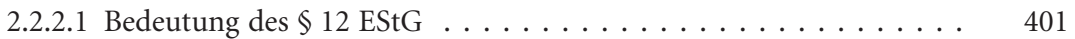

2.2.2.2 Aufteilungsgebot bei gemischter Veranlassung . . . . . . . . . . 402

2.3 Praktisch besonders bedeutsame Erwerbsaufwendungen . . . . . . . . . . . 405

2.3.1 Gesetzgeberische Typisierungen . . . . . . . . . . . . . . . . 405

2.3.2 Arbeitsmittel . . . . . . . . . . . . . . . . . . . . . . 405

2.3.3 Arbeitszimmer . . . . . . . . . . . . . . . . . . . . . 406

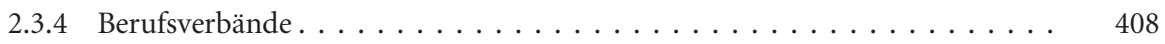

2.3 .5 Bewirtung . . . . . . . . . . . . . . . . . . . . . 409

2.3.6 Doppelte Haushaltsführung: . . . . . . . . . . . . . . . . . . . . . . 409

2.3.7 Fahrten zwischen Wohnung und Erwerbsstätte . . . . . . . . . . . . 411

2.3 .8 Fort- und Ausbildung . . . . . . . . . . . . . . . . . . . . . 412

2.3 .9 Geschenke. . . . . . . . . . . . . . . . . . . . . . . . 415

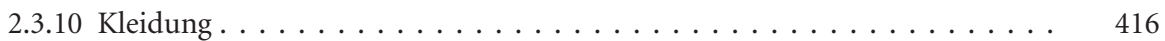

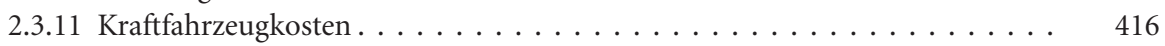

2.3.12 Reisekosten . . . . . . . . . . . . . . . . . . . . . . 418

2.3 .13 Telefonkosten . . . . . . . . . . . . . . . . . . . . . . . 419

2.3 .14 Umzugskosten . . . . . . . . . . . . . . . . . . . . . . . . . . 419

2.3.15 Verlust von Wirtschaftsgütern … . . . . . . . . . . . . . 419

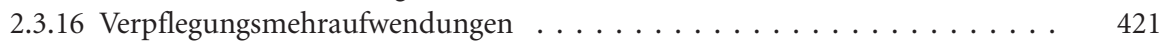

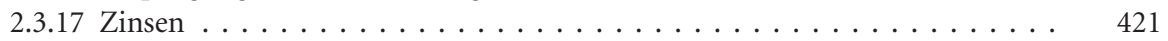

2.4 Nichtabziehbare Erwerbsaufwendungen . . . . . . . . . . . . . . . . 423

2.4 .1 Allgemeine Regeln . . . . . . . . . . . . . . . . . . . . . 423

2.4.2 Besondere Regeln für privat mitveranlasste Erwerbsaufwendungen . . . . . . . 425

2.4.3 Besondere Regeln zum Schutz der Gesamtrechtsordnung . . . . . . . . . . 426

2.4.4 Besondere Regeln zum Schutz des Steueraufkommens gegen Steuer-

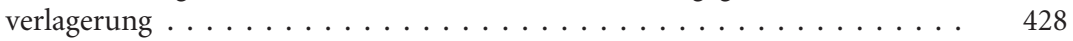

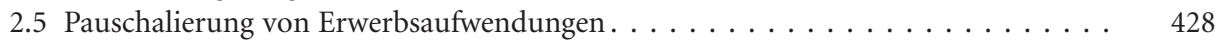

III. Ermittlung der Überschusseinkünfte $(\$ \$ 8-9$ a EStG) $\ldots \ldots \ldots \ldots \ldots \ldots$

1. Allgemeine Regeln . . . . . . . . . . . . . . . . . . . . . . . . . . . . 429

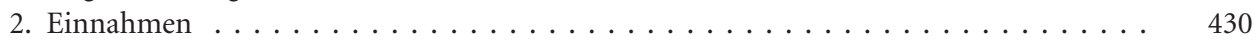

3. Werbungskosten ............................ 432 
Seite

G. Die einzelnen Einkunftsarten . . . . . . . . . . . . . . . . . . . . . . . . . 434

I. Einführung in das Einkunftsartenrecht . . . . . . . . . . . . . . . . . . . . . 435

II. Gewinneinkünfte $(\$ 2$ II 1 Nr. 1 EStG $) \ldots \ldots \ldots \ldots$

1. Einkünfte aus Land- und Forstwirtschaft $(\$ \$ 13-14 \mathrm{a}$ EStG) . . . . . . . . . . . . . . . . 436

1.1 Bestimmung und Privilegierung der Einkünfte aus Land- und Forstwirtschaft . . . . 436

1.2 Gewinnermittlung nach Durchschnittssätzen $(\$ 13 \mathrm{a}$ EStG $) \ldots \ldots$. . . . . . . . . . . . . . . . . . . . . . . .

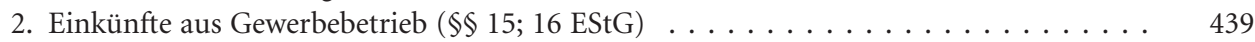

2.1 Allgemeine Begriffsbestimmung . . . . . . . . . . . . . . . . . . . . . . . . . . . . . . . . . . . . . . . . . . .

2.2 Überblick über die Arten der gewerblichen Einkünfte . . . . . . . . . . . . . . . . . . . . . . . . . . . . . . . . . . . . . . . . . .

3. Einkünfte aus selbständiger Arbeit $(\$ 18 \mathrm{EStG}) \ldots \ldots \ldots \ldots$. . . . . . . . . . . . . . 443

III. Überschusseinkünfte $(\$ 2$ II 1 Nr. 2 EStG $) \ldots \ldots \ldots \ldots \ldots$

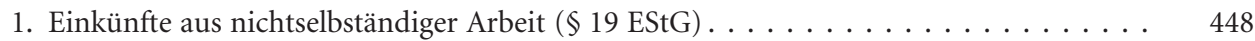

1.1 Der Begriff des Arbeitnehmers . . . . . . . . . . . . . . . . . . . . . . . . . . . 448

1.2 Arbeitslohn. . . . . . . . . . . . . . . . . . . . . . . 450

1.2.1 Durch die nichtselbständige Beschäftigung veranlasste Einnahmen . . . . . . 450

1.2 .2 Versorgungsbezüge . . . . . . . . . . . . . . . . . . . . 453

1.2.3 Lohnsteuerpauschalierungen, insb. geringfügige Beschäftigung . . . . . . . 455

2. Einkünfte aus Kapitalvermögen mit Abgeltungsteuer $(\$ \$ 20 ; 32 d ; 43$ V 1 EStG) . . . . 456

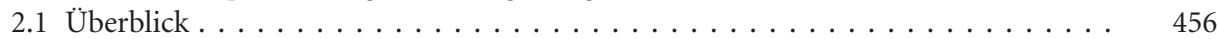

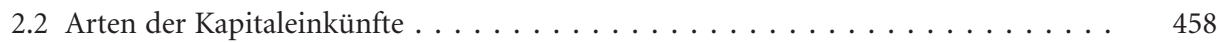

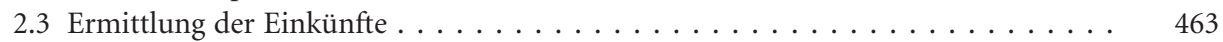

2.4 Reichweite der Abgeltungsteuer . . . . . . . . . . . . . . . . . . . . . . . . . . . . . 464

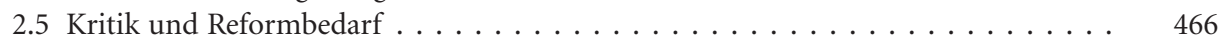

3. Einkünfte aus Vermietung und Verpachtung $(\$ 21 \mathrm{EStG})$. . . . . . . . . . . . . . . . . . . . . . . . . . . . . . . . . . . . .

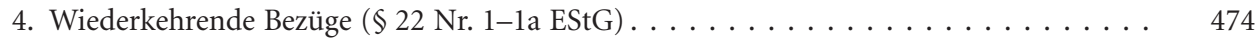

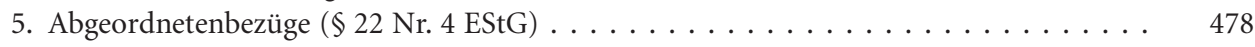

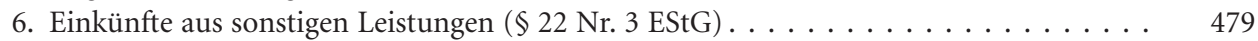

7. Einkünfte aus der Veräußerung von Privatvermögen . . . . . . . . . . . . . . . . . . . . 481

7.1 Ungleiche Erfassung von Veräußerungseinkünften . . . . . . . . . . . . . . . . . . 481

7.2 Einkünfte aus der Veräußerung von Anteilen an Kapitalgesellschaften ( $\$ 17$ EStG) . 481

7.3 Einkünfte aus privaten Veräußerungsgeschäften $(\$ \$ 22$ Nr. 2; 23 EStG) . . . . . . . . 484

7.4 Zur gleichmäßigen Besteuerung von Veräußerungseinkünften . . . . . . . . . . . . . . . . 486

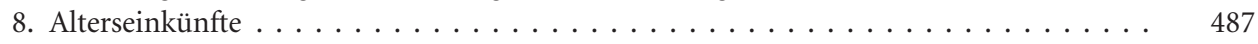

8.1 Überblick . . . . . . . . . . . . . . . . . . . . . . . . . . . . . . 488

8.2 Rürup-Kommission und geltende Rechtslage nach dem Alterseinkünftegesetz . . . . 488

8.3 Kritik und Reformüberlegungen . . . . . . . . . . . . . . . . . . . . . . 491

IV. Gemeinsame Vorschriften zu allen Einkunftsarten . . . . . . . . . . . . . . . . . . 492

V. Konkurrenzen mehrerer Einkunftsarten . . . . . . . . . . . . . . . . . . . . . . . 492

H. Private Abzüge . . . . . . . . . . . . . . . . . . . . . . . . . . . . 494

1. Allgemeines zu den privaten Abzügen . . . . . . . . . . . . . . . . . . . . . . . . . . . 494

2. Abzugsfähigkeit sog. Sonderausgaben . . . . . . . . . . . . . . . . . . . . . . . . . . . . . . . . . . . . . . . . . .

3. Außergewöhnliche Belastungen $(\$ \$ 33 ; 33 a ; 33 b$ EStG $) \ldots \ldots \ldots \ldots$. . . . . . . . . . . 498 


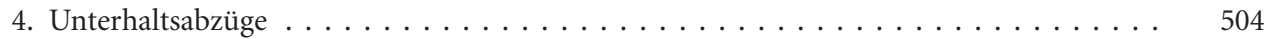

4.1 Allgemeiner Unterhaltsabzug $(\$ 33 \mathrm{a}$ I EStG $) \ldots \ldots \ldots \ldots \ldots \ldots \ldots$

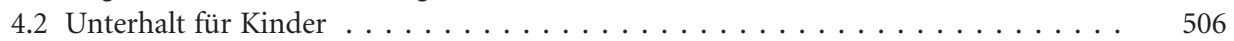

4.2.1 Allgemeine Voraussetzungen $(\$ 32 \mathrm{I}-\mathrm{V}$ EStG $) \ldots \ldots \ldots \ldots \ldots$

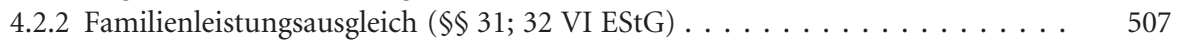

4.2.3 Zusätzliche Abzüge für den Kindesunterhalt . . . . . . . . . . . . . . . . . 509

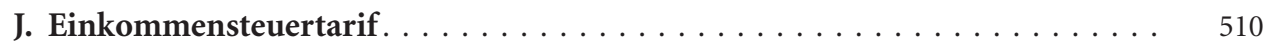

1. Der linear-progressive Tarif . . . . . . . . . . . . . . . . . . 511

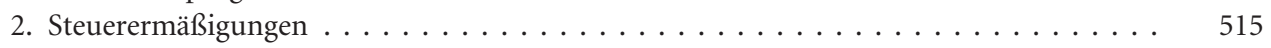

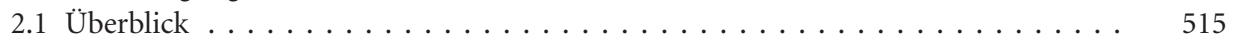

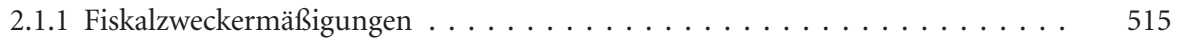

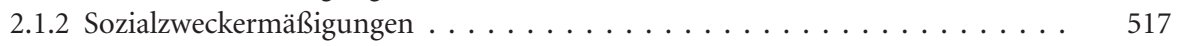

2.2 Steuerermäßigungen für außerordentliche Einkünfte $(\$ \$ 34 ; 34 \mathrm{~b} \mathrm{EStG}) \ldots \ldots \ldots \ldots 517$

2.3 Begünstigung nicht entnommener Gewinne $(\$ 34 \mathrm{a} \mathrm{EStG)} \mathrm{\ldots} \mathrm{.} \mathrm{.} \mathrm{.} \mathrm{.} \mathrm{.} \mathrm{.} \mathrm{.} \mathrm{.} \mathrm{.} \mathrm{.} \mathrm{.} 519$

2.4 Steuerermäßigung bei Auslandseinkünften $(\$ \$ 34 \mathrm{c} ; 34 \mathrm{~d}$ EStG) $\ldots \ldots \ldots \ldots \ldots . \ldots . \ldots 22$

2.5 Pauschale Anrechnung der Gewerbesteuer $(\$ 35 \mathrm{EStG}) \ldots \ldots \ldots \ldots \ldots$

3. Veranlagung von Ehegatten . . . . . . . . . . . . . . . . . . 524

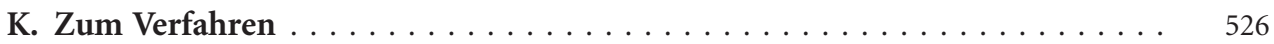

L. Annexsteuer: Kirchensteuer . . . . . . . . . . . . . . . . . . . . . . . 529

1. Arten der Kirchenfinanzierung . . . . . . . . . . . . . . . . . . . . 530

2. Das Besteuerungsrecht der Religionsgemeinschaften nach Art. 140 GG

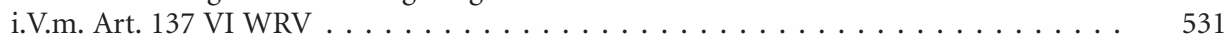

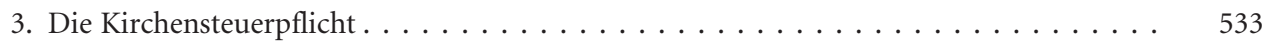

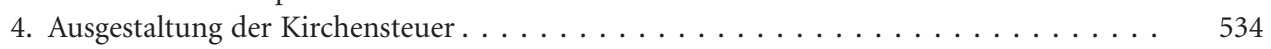

5. Verwaltung der Kirchensteuer, Verfahren $\ldots \ldots \ldots \ldots \ldots \ldots \ldots$

\section{\$9 Steuerrechtliche Gewinnermittlung (Bilanzsteuerrecht)}

A. Überblick über das System betrieblicher Gewinnermittlung . . . . . . . . . . 541

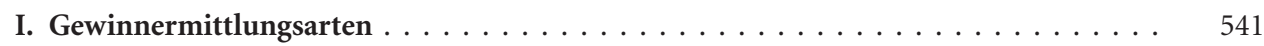

II. Subjektiver Anwendungsbereich der Gewinnermittlungsarten . . . . . . . . . . . 542

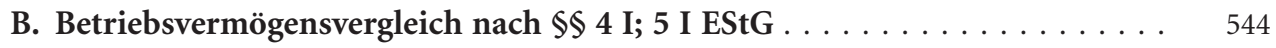

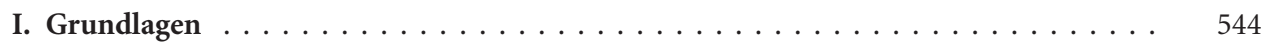

1. Gewinn i.S.d. $\$ 4$ I 1 EStG $\ldots \ldots \ldots \ldots \ldots \ldots \ldots \ldots \ldots \ldots \ldots$

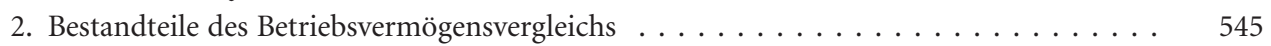

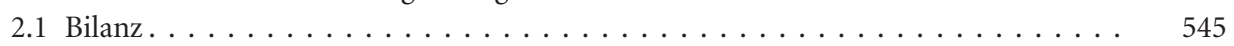

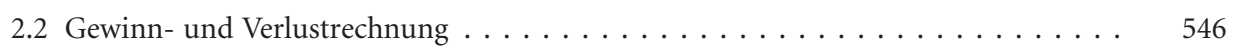

3. Technik der Bilanzierung und doppelten Buchführung . . . . . . . . . . . . 547 
II. Maßgeblichkeit der handelsrechtlichen Grundsätze ordnungsmäßiger Buchführung

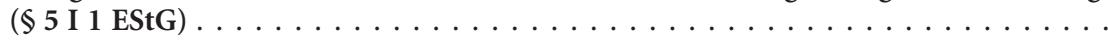

Seite

1. Prinzipielle Maßgeblichkeit der handelsrechtlichen GoB für die Steuerbilanz -

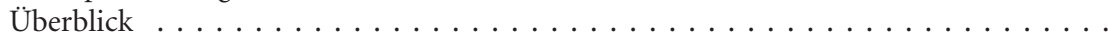

2. Grundsätze ordnungsmäßiger Buchführung und Bilanzierung $\ldots \ldots \ldots \ldots \ldots$

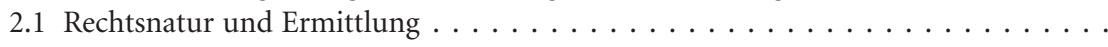

2.2 Reichweite der Verweisung gemäß $\$ 5$ I 1 EStG $\ldots \ldots \ldots \ldots \ldots \ldots \ldots$

2.3 Insbesondere: GoB und Europäische Bilanzrichtlinien, Unzuständigkeit des

EuGH in Steuerstreitigkeiten . . . . . . . . . . . . . . . . . . . . . 554

2.4 Formelle Grundsätze . . . . . . . . . . . . . . . . . . . . . . 556

2.5 Materielle Grundsätze . . . . . . . . . . . . . . . . . . . . . . 557

2.5.1 Prinzipien der Richtigkeit und Vollständigkeit; GoB der Nichtbilanzierung schwebender Geschäfte. . . . . . . . . . . . . . . . . . . . 557

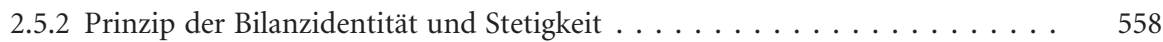

2.5.3 Vorsichts-, Realisations- und Imparitätsprinzip; Anschaffungswertprinzip . . 558

2.5.4 Wirtschaftliche Betrachtungsweise . . . . . . . . . . . . . . . . . 560

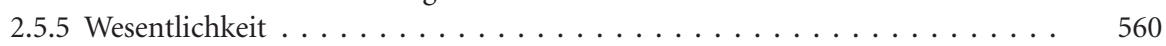

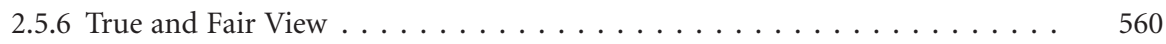

2.5 .7 Nominalwertprinzip . . . . . . . . . . . . . . . . . . . . . . . . . . . . . 563

2.5 .8 Stichtagsprinzip . . . . . . . . . . . . . . . . . . . . 563

3. Grenzen der Maßgeblichkeit handelsrechtlicher Bilanzierungsregeln für das Steuerrecht 564

3.1 Vorrang expliziter steuerrechtlicher Ansatz- und Bewertungsvorschriften

$(\$ 4 \mathrm{I} 9 ; \S 5 \mathrm{VI} \mathrm{EStG)} \ldots \ldots \ldots \ldots \ldots \ldots \ldots$

3.2 Insbesondere: Steuerrechtliche Wahlrechte $(\$ 5$ I 1 Hs. 2 EStG) $\ldots \ldots \ldots \ldots \ldots \ldots 5$

3.3 Handelsrechtliche Wahlrechte . . . . . . . . . . . . . . . . . . . . 567

4. Rechtfertigung des Maßgeblichkeitsprinzips . . . . . . . . . . . . . . . 569

5. Zur Zukunft des Maßgeblichkeitsprinzips und Überlegungen de lege ferenda

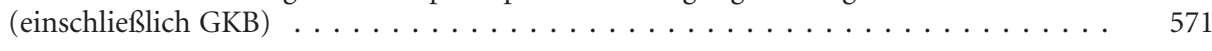

III. Ansatz von Wirtschaftsgütern des Betriebsvermögens und sonstigen Bilanzposten

(Bilanzierung dem Grunde nach) . . . . . . . . . . . . . . . . . . . . . . . . . . . . . . . . . . . . . . .

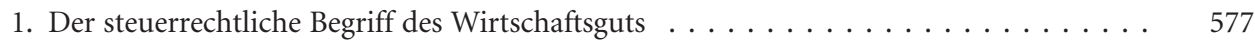

1.1 Vermögensgegenstand - Wirtschaftsgut . . . . . . . . . . . . . . . . . . . . . . . 577

1.2 Besonderheiten einzelner Wirtschaftsgüter . . . . . . . . . . . . . . . . . . . . . . . . . . . . . . . . . . . . . . .

1.2.1 Immaterielle Wirtschaftsgüter . . . . . . . . . . . . . . . . . . . 578

1.2.2 Selbständige Vermögensgegenstände und unselbständige Teile, insb.:

Grundstücke und Gebäude, selbständige Gebäudeteile und selbständige

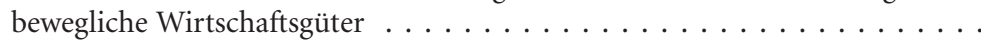

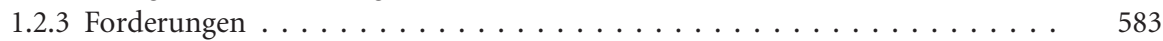

1.3 Subjektive Zurechnung von Wirtschaftsgütern . . . . . . . . . . . . . . . . . . . . . . . . . . . . . . . . . . . . . . . . . . . . . .

2. Passivierung von Verbindlichkeiten und Rückstellungen . . . . . . . . . . . . . . . . . . . . . . . . . . . . . . .

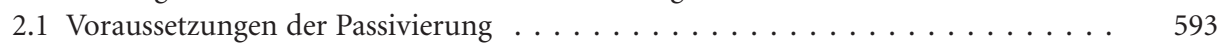

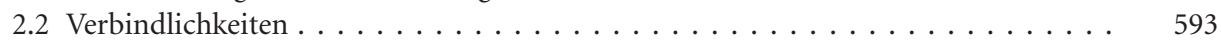

2.3 Rückstellungen . . . . . . . . . . . . . . . . . . . . . . . . . . . . . . . . . . . . 597

2.3.1 Überblick über die Passivierungsvoraussetzungen . . . . . . . . . . . . . . . . . . . . . . . . . 597

2.3.2 Außenverpflichtung. . . . . . . . . . . . . . . . . . . . . . . 598

2.3.3 Rechtliche Entstehung und wirtschaftliche Verursachung . . . . . . . . . . 600

2.3.4 Wahrscheinlichkeit der Inanspruchnahme . . . . . . . . . . . . . . 606 
2.3.5 Wesentlichkeit kein Kriterium . . . . . . . . . . . . . . . . . . . 607

2.3.6 Steuerrechtliche Sondervorschriften: $₫ 5$ III-IVb, $\S 6$ a EStG . . . . . . . . . 607

2.3.7 Insb.: angeschaffte Rückstellungen (Verpflichtungsübernahme,

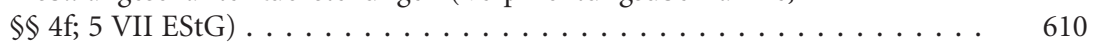

2.3.8 Auflösung von Rückstellungen . . . . . . . . . . . . . . . . . . . . . 614

3. Rechnungsabgrenzungsposten . . . . . . . . . . . . . . . . . . 614

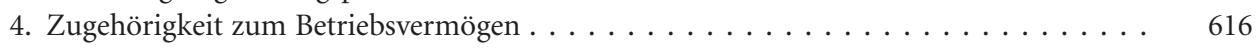

IV. Bewertung von Wirtschaftsgütern und sonstigen Bilanzposten

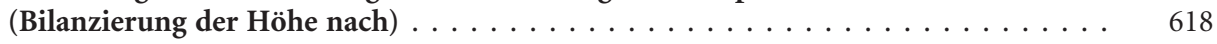

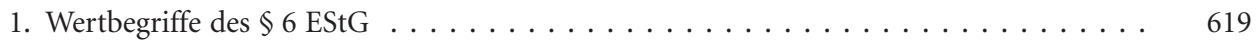

1.1 Anschaffungskosten $(\$ 6$ I Nr. 1 Satz 1, Nr. 2 Satz 1 EStG $) \ldots \ldots \ldots \ldots$. . . . . . . . . . 619

1.2 Herstellungskosten ( $\$ 6$ I Nr. 1 Satz 1 , Nr. 1a, Nr. 2 Satz 1 EStG) . . . . . . . . . 625

1.3 Teilwert ( $\$ 6$ I Nr. 1 Satz 2 u. 3, Nr. 2 Satz 2, Nr. 4 Satz 1 Hs. 1, 5, 7 EStG) . . . . . 628

1.4 Gemeiner Wert (\$6 I Nr. 4 Satz 1 Hs. 2, Nr. 5a, IV, VI 1 EStG) . . . . . . . . . . . 629

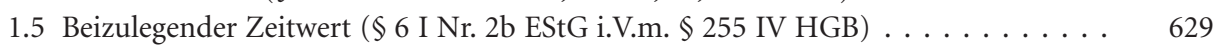

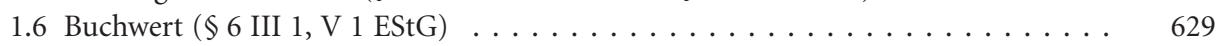

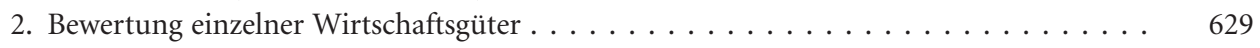

2.1 Einzelbewertungsgrundsatz und Ausnahmen (insb. Bewertungseinheiten,

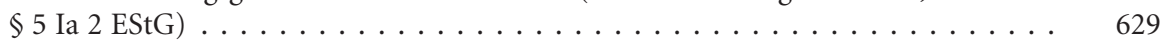

2.1 .1 Überblick . . . . . . . . . . . . . . . . . . . . . . . . . . . . 629

2.1.2 Insb.: Bewertungseinheiten gem. $\S 5$ Ia 2 EStG . . . . . . . . . . . . 630

2.2 Abnutzbares Anlagevermögen $(\$ 6$ I Nr. 1 EStG) $\ldots \ldots \ldots \ldots \ldots \ldots \ldots$

2.3 Andere aktive Wirtschaftsgüter $(\$ 6$ I Nr. 2 EStG $) \ldots \ldots \ldots \ldots \ldots 34$

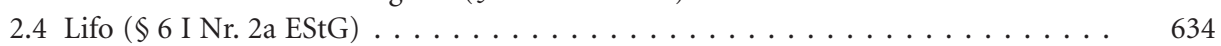

2.5 Passive Wirtschaftsgüter $(\$ 6$ I Nr. 3, 3a EStG $) \ldots \ldots \ldots \ldots \ldots \ldots \ldots \ldots$

3. Abschreibungen und Zuschreibungen . . . . . . . . . . . . . . . . 641

3.1 Absetzung für Abnutzung (AfA) und Substanzverringerung (AfS) $\ldots \ldots \ldots \ldots .641$

3.2 Teilwertabschreibungen und Wertaufholungen . . . . . . . . . . . . . . 647

3.3 Sonderabschreibungen und erhöhte Absetzungen . . . . . . . . . . . . . . . 649

3.4 Subjektive Abschreibungsberechtigung . . . . . . . . . . . . . . 650

V. Entnahmen und Einlagen . . . . . . . . . . . . . . . . . . . 651

1. Entnahme- und Einlagefähigkeit von Wirtschaftsgütern, Nutzungen und Leistungen . . 651

2. Bewertung von Entnahmen und Einlagen . . . . . . . . . . . . . . 654

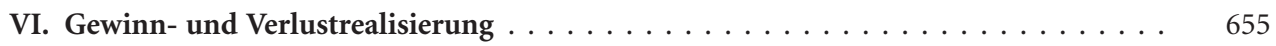

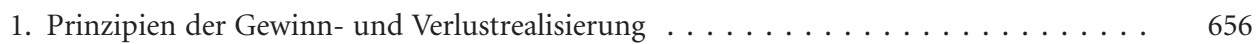

2. Gewinnrealisierung bei Umsatzgeschäften (Lieferung und Leistung) . . . . . . . . . . . . . . . 657

3. Aufgeschobene Gewinnrealisierung . . . . . . . . . . . . . . . . 661

3.1 Aufschub der Besteuerung stiller Reserven bei demselben Stpfl. (RfE; $\$ \$ 6 b, 6 c$;

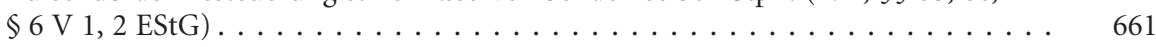

3.2 Übergang stiller Reserven auf andere Steuerrechtssubjekte . . . . . . . . . . . 663

4. Besteuerung stiller Reserven ohne Realisationsakt als ultima ratio . . . . . . . . . . . 665

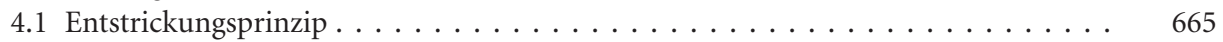

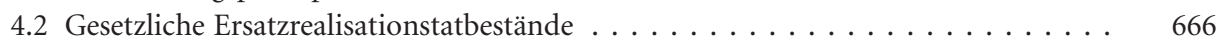

4.2.1 Entnahme i.S.d. $\$ 4$ I 2 EStG $\ldots \ldots \ldots \ldots \ldots \ldots \ldots \ldots 6 \ldots \ldots \ldots \ldots$ 
Seite

4.2.2 Betriebsaufgabe als Totalentnahme ( $\$ \$ 14 ; 14 \mathrm{a}$ III; 16 III; 18 III EStG); Betriebsunterbrechung und Betriebsverpachtung ( $\$ 16$ IIIb EStG) . . . . . . 666

4.2.3 Ausschluss oder Beschränkung des Besteuerungsrechts der Bundesrepublik Deutschland $(\$ \$ 4$ I 3; 16 IIIa EStG; $\$ 12$ I KStG) . . . . . . . . . . . . . . . 668

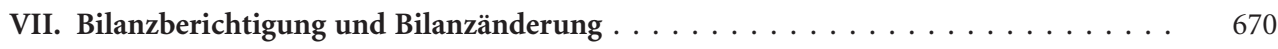

\section{Besonderheiten der bilanziellen Gewinnermittlung bei Kapital-}

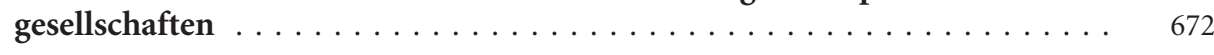

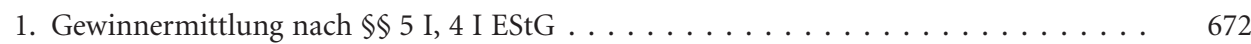

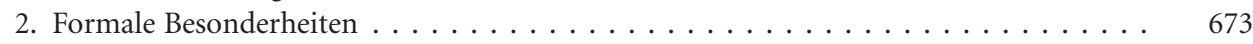

3. Besondere Bilanzierungs- und Bewertungsvorschriften . . . . . . . . . . . . . . . 674

D. Vereinfachte Gewinnermittlung durch betriebliche Überschussrechnung

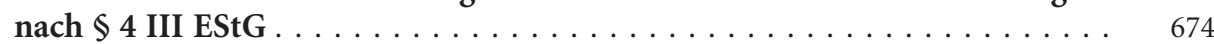

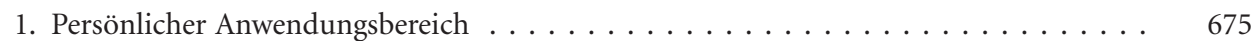

2. Prinzipien der Gewinnermittlung nach $\S 4$ III EStG . . . . . . . . . . . . . . . . . . 676

3. Betriebseinnahmen und -ausgaben in der Kassenrechnung . . . . . . . . . . . . . 677

4. Zeitliche Erfassung von Betriebseinnahmen und Betriebsausgaben nach dem Zu- und Abflussprinzip $(\$ 11 \mathrm{EStG}) \ldots \ldots \ldots \ldots \ldots$

5. Abweichungen vom $\mathrm{Zu}$ - und Abflussprinzip . . . . . . . . . . . . . . . . . . . . . . . . . . . . . . . . . . . . . .

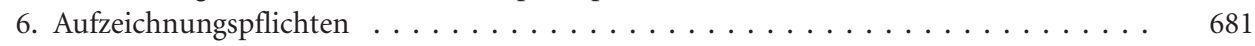

7. Wechsel der Gewinnermittlungsart . . . . . . . . . . . . . . . . . . . . . . 681

\section{$\$ 10$ Besteuerung von Mitunternehmerschaften}

\section{A. Dualismus der Unternehmensbesteuerung $\ldots \ldots \ldots \ldots \ldots$}

B. Besteuerung von Mitunternehmerschaften $\ldots \ldots \ldots 686$

I. Besteuerung der laufenden Einkünfte von Mitunternehmern (\$\$ 15 I 1 Nr. 2, III; 15a; 13 VII; 18 IV 2 EStG) . . . . . . . . . . . . . . . . . . . 686

1. Besteuerung der Mitunternehmerschaft nach dem Transparenzprinzip . . . . . . . . . 687

2. Zweistufigkeit der Einkünfte von Mitunternehmern . . . . . . . . . . . . . . . . . . 689

3. Mitunternehmerschaft als Unterfall der Personengesellschaft . . . . . . . . . . . . . 690

4. Qualifikation und Zurechnung der Einkünfte von Mitunternehmern . . . . . . . . . . 690

4.1 Der Begriff des Mitunternehmers . . . . . . . . . . . . . . . . . . . . . . . 690

4.1.1 Funktion des Mitunternehmerbegriffs . . . . . . . . . . . . . . . . . . . . . . . 690

4.1.2 Zivilrechtliche Gesellschafterstellung . . . . . . . . . . . . . . . . . . . . 691

4.1.3 Mitunternehmerrisiko und Mitunternehmerinitiative . . . . . . . . . . . . . . 692

4.2 Zweistufige Qualifikation der Einkünfte von Mitunternehmern . . . . . . . . . . . . . . 693

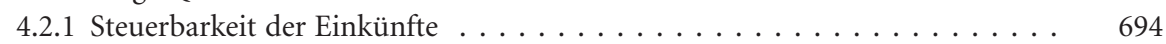

4.2.2 Qualifikation der Einkunftsart. . . . . . . . . . . . . . . . . . . . . 694

4.3 Zurechnung der Einkünfte von Mitunternehmern . . . . . . . . . . . . . . . . . . . . . 696

5. Arten der Mitunternehmerschaft . . . . . . . . . . . . . . . . . . . . . 698

6. Ermittlung der Einkünfte von Mitunternehmern . . . . . . . . . . . . . . . . . . . 705

6.1 Zweistufige Ermittlung der Einkünfte von Mitunternehmern . . . . . . . . . . . 706 


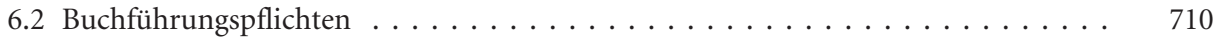

6.3 Einzelheiten zur ersten Stufe der Einkünfteermittlung . . . . . . . . . . . . 711

6.4 Einzelheiten zur zweiten Stufe der Einkünfteermittlung . . . . . . . . . . . . . . 714

II. Besteuerung von Sondervorgängen: Gründung, Umstrukturierungen, Veräußerungen, Erbfolge, Betriebsaufgabe und Realteilung . . . . . . . . . . . 721

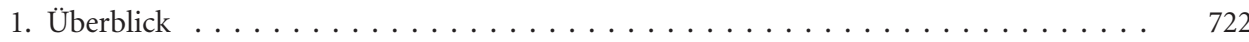

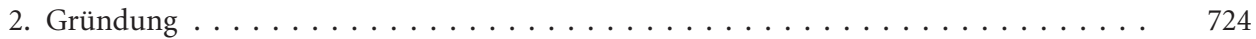

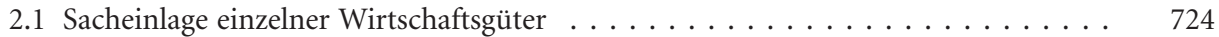

2.2 Einbringung von Sachgesamtheiten (Betrieb, Teilbetrieb oder Mitunternehmer-

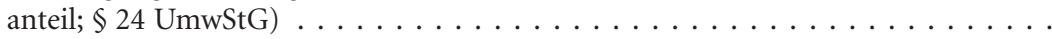

2.3 Beitritt eines neuen Gesellschafters in eine bestehende Personengesellschaft; Aufnahme in ein Einzelunternehmen . . . . . . . . . . . . . . .

3. Übertragung von Einzelwirtschaftsgütern innerhalb der Mitunternehmerschaft und zwischen beteiligungsidentischen Schwestergesellschaften . . . . . . . . . .

4. Übertragung von Anteilen an einer Mitunternehmerschaft . . . . . . . . . . . . . . .

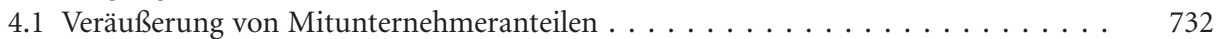

4.2 Ausscheiden von Gesellschaftern gegen (Bar-)Abfindung . . . . . . . . . . . 733

4.3 Unentgeltliche Übertragung von Mitunternehmeranteilen . . . . . . . . . . . . . . . . 734

4.4 Tod eines Mitunternehmers und vorweggenommene Erbfolge . . . . . . . . . . 735

5. Auflösung und Realteilung (einschließlich Sachwertabfindung) . . . . . . . . . . 735

5.1 Aufgabe des Gewerbebetriebs der Mitunternehmerschaft und Liquidation . . . . . . 735

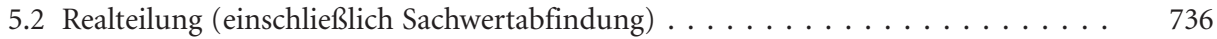

III. Begünstigung des nicht entnommenen Gewinns $(\$ 34 \mathrm{a}$ EStG $) \ldots \ldots \ldots \ldots \ldots$

\section{$\$ 11$ Körperschaftsteuer}

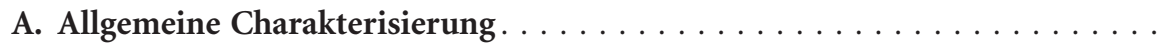

I. Dualismus der Unternehmensbesteuerung durch Nebeneinander von Trennungs-

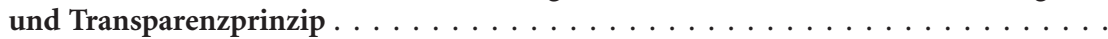

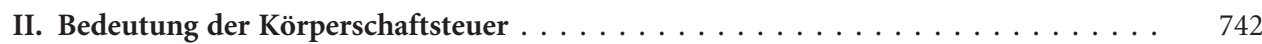

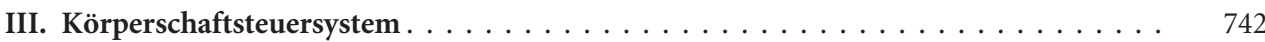

1. Vermeidung wirtschaftlicher Doppelbelastung . . . . . . . . . . . . . . . . . . 742

2. Frühere Körperschaftsteuersysteme in Deutschland . . . . . . . . . . . . . 744

3. Seit 2001: Klassisches System mit pauschaler Entlastung auf Anteilseignerebene . . . . 744

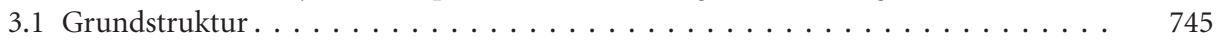

3.2 Gründe für den Systemwechsel vom Anrechnungsverfahren zu einem klassischen System mit Teilentlastung . . . . . . . . . . . . . . . . . . . . . . . . . . 747

3.3 Bewertung der Belastungswirkungen beim Anteilseigner . . . . . . . . . . . 748

B. Subjektive Steuerpflicht $\ldots \ldots \ldots \ldots \ldots \ldots \ldots \ldots \ldots \ldots \ldots \ldots$

I. Körperschaftsteuersubjekte i.S.d. $\$ \$ 1$ I Nr. 1-6, 3 KStG . . . . . . . . . . . . . 750

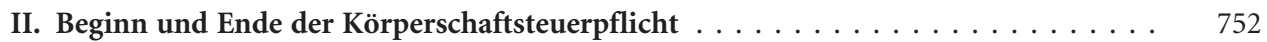

III. Juristische Personen des Öffentlichen Rechts (Öffentliche Unternehmen) . . . . . . 752 
Seite

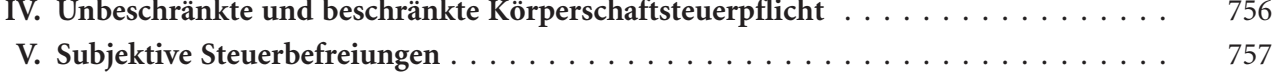

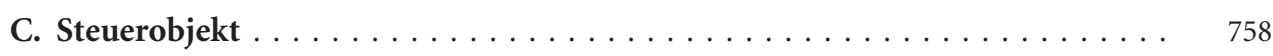

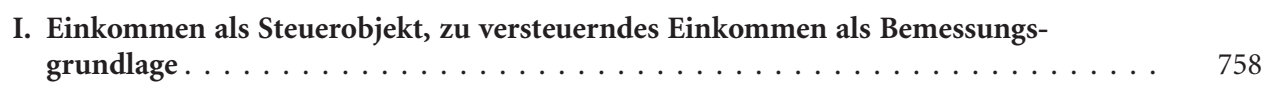

II. Ermittlung des Einkommens . . . . . . . . . . . . . . . . . . . . . . . . . . 759

1. Allgemeines . . . . . . . . . . . . . . . . . . . . . . . . . . 759

2. Objektive Steuerbefreiungen, insb. Steuerfreiheit von Beteiligungserträgen $(\$ 8 b \mathrm{KStG})$. 759

3. Unterscheidung zwischen betrieblichen und außerbetrieblichen Vermögensmehrungen

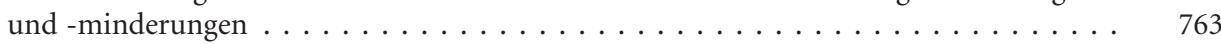

3.1 Abgrenzung von Betriebsausgaben, Gewinnausschüttungen und betriebsfremden

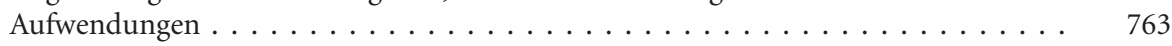

3.2 Kapitalerhöhungen und Gesellschaftereinlagen, Einlagenrückgewähr . . . . . . . . . 764

4. Besondere Vorschriften über den Abzug von Aufwendungen . . . . . . . . . . . . . . . . 765

4.1 Abziehbare und nicht abziehbare Aufwendungen nach $\$ \$ 9 ; 10 \mathrm{KStG} \ldots \ldots . . . . . .765$

4.2 Beschränkung des Abzugs von Finanzierungsaufwand im Konzern (Zinsschranke, $\S 4 \mathrm{~h} \mathrm{EStG} ;$ \$ $\mathrm{a}$ I KStG) und Gesellschafterfremdfinanzierung (\$ 8a II, III KStG) . . 767

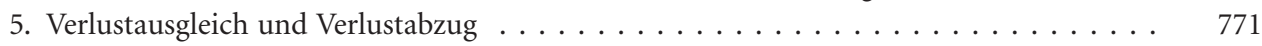

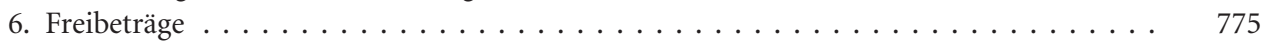

7. Verdeckte Gewinnausschüttungen und verdeckte Einlagen . . . . . . . . . . . . . . . 775

7.1 Verdeckte Gewinnausschüttungen . . . . . . . . . . . . . . . . . . . . . . . . 775

7.1.1 Voraussetzungen der verdeckten Gewinnausschüttung . . . . . . . . . . . . . . . . 775

7.1.2 Rechtsfolgen der verdeckten Gewinnausschüttung . . . . . . . . . . . . . . . . . . . . . 784

7.2 Verdeckte Einlagen . . . . . . . . . . . . . . . . . . . . . . 786

8. Besondere Fälle der Gewinnrealisierung und ihres Aufschubs . . . . . . . . . . . . . . . . . . . . . . . . . . . . . . . .

8.1 Liquidation $(\$ 11 \mathrm{KStG}) \ldots \ldots \ldots \ldots \ldots \ldots \ldots \ldots$

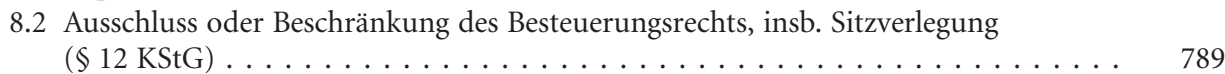

8.3 Eintritt in eine subjektive Steuerbefreiung $(\$ 13 \mathrm{KStG}) \ldots \ldots \ldots \ldots$

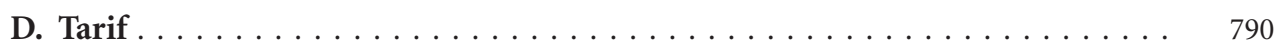

\section{$\$ 12$ Gewerbesteuer}

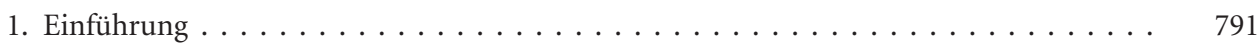

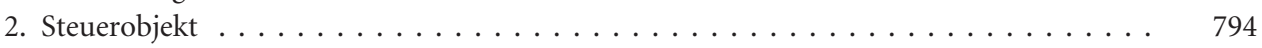

2.1 Stehender Gewerbebetrieb . . . . . . . . . . . . . . . . . . . . . . . . . . . 794

2.2 Reisegewerbebetrieb . . . . . . . . . . . . . . . . . . . . . . . . . . . . . . . . . . . . . . . . . . . . . . . . . . . .

2.3 Mehrheit von Gewerbebetrieben . . . . . . . . . . . . . . . . . . . . . . . . . . . . . . . . . . . . . . . . . . . .

2.4 Beginn und Ende der Besteuerung . . . . . . . . . . . . . . . . . . . . . . . . . . . . . . . . . . . . . . . . . . . . . . . . . . .

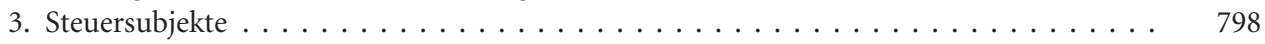

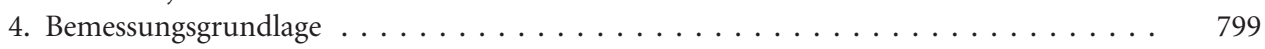

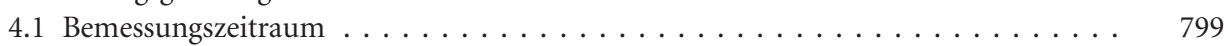

4.2 Gewerbeertrag $(\$ 7 \mathrm{GewStG}) \ldots \ldots \ldots \ldots \ldots \ldots \ldots \ldots$

4.2 .1 Allgemeine Modifikationen . . . . . . . . . . . . . . . . . . 801 
Seite

4.2.2 Gesetzliche Sonderregelungen bei der Ermittlung des Gewerbeertrags

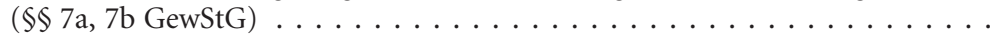

802

4.2 .3 Hinzurechnungen $(\$ 8 \mathrm{GewStG}) \ldots \ldots \ldots \ldots \ldots \ldots$

4.2 .4 Kürzungen $(\$ 9 \mathrm{GewStG}) \ldots \ldots \ldots \ldots \ldots \ldots$

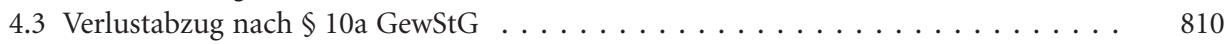

4.4 Steuermessbetrag $(\$ 11 \mathrm{GewStG}) \ldots \ldots \ldots \ldots \ldots 1 \ldots \ldots \ldots$

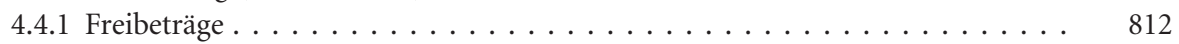

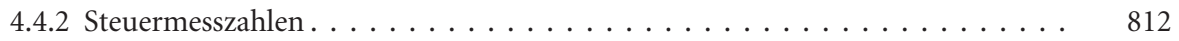

4.4 .3 Verfahren. . . . . . . . . . . . . . . . . . . . . . . . . . . . . . . . . . . . . . . . . . . .

5. Zerlegung des einheitlichen Steuermessbetrags . . . . . . . . . . . . . . . . . . . . . . . . . . . . . . . . .

6. Entstehung, Festsetzung und Erhebung . . . . . . . . . . . . . . . . . . . . . . . . . . . . . . . . . .

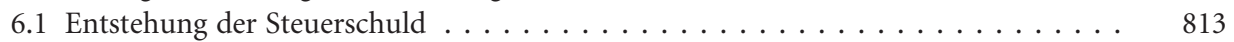

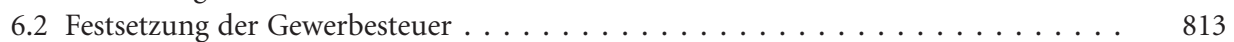

6.3 Vorauszahlungen und Abrechnung . . . . . . . . . . . . . . . . . . . . . . . . . . . . . . . . . . . . . . . .

7. Steuererklärungen . . . . . . . . . . . . . . . . . . . . . . . . . . . . . . 814

\section{$\S 13$ Rechtsformabhängige Unternehmensbesteuerung}

\section{A. Grundsätzliche Unterschiede in der Besteuerung von Personenunternehmen} und Kapitalgesellschaften

I. Unterschiede in der laufenden Besteuerung von Personenunternehmen und Kapitalgesellschaften

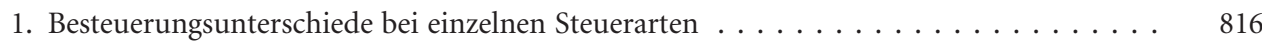

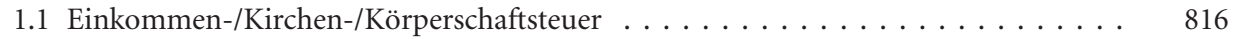

1.2 Gewerbesteuer . . . . . . . . . . . . . . . . . . . . . 819

2. Zusammenfassender Vergleich laufender Besteuerungsunterschiede . . . . . . . . . 820

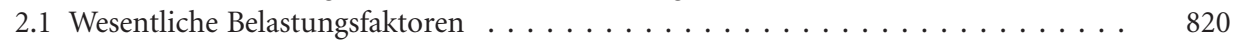

2.2 Bedeutung des Thesaurierungs- und Entnahme-/Ausschüttungsverhaltens . . . . . 821

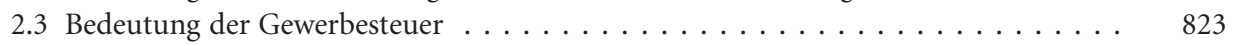

II. Unterschiede in der Besteuerung von Sondervorgängen . . . . . . . . . . . . . 823

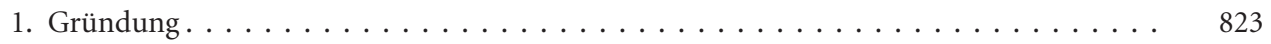

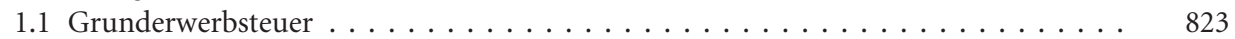

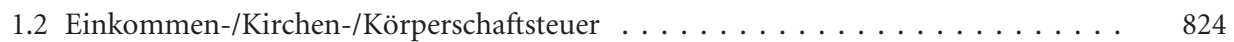

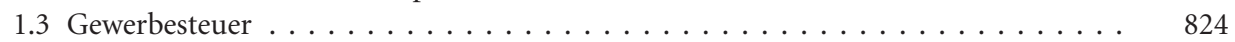

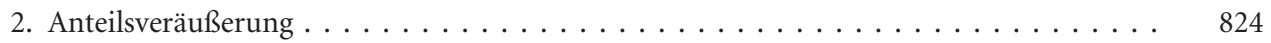

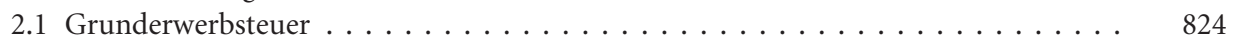

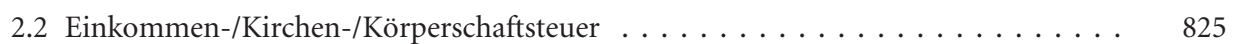

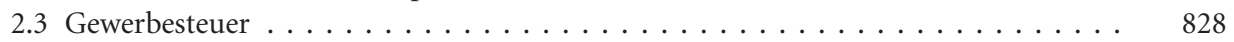

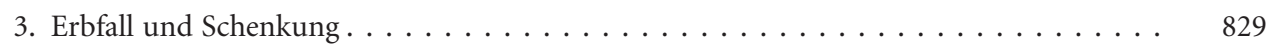

3.1 Einkommen-/Kirchen-/Körperschaftsteuer . . . . . . . . . . . . . . . . 829

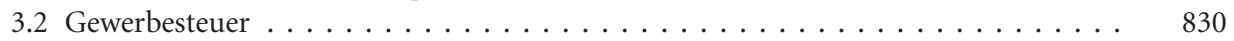

3.3 Erbschaft- und Schenkungsteuer . . . . . . . . . . . . . . . . . . . 830

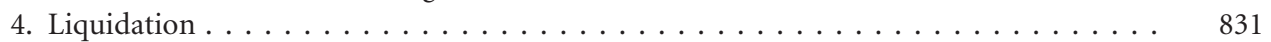

4.1 Einkommen-/Kirchen-/Körperschaftsteuer . . . . . . . . . . . . . . . . . . . . . . . . . . . . . . . . .

4.2 Gewerbesteuer . . . . . . . . . . . . . . . . . . . . 832 
B. Besteuerung zusammengesetzter Unternehmensformen . . . . . . . . . 832

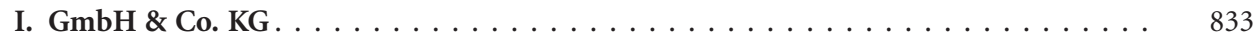

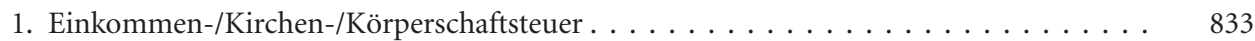

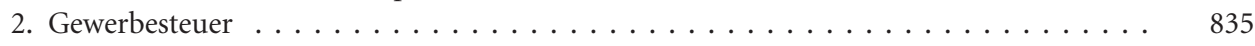

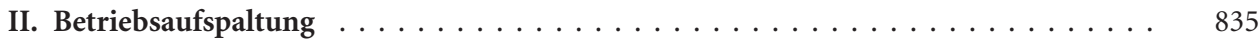

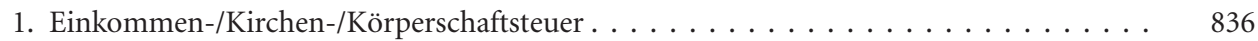

2. Gewerbesteuer . . . . . . . . . . . . . . . . . . . . . 839

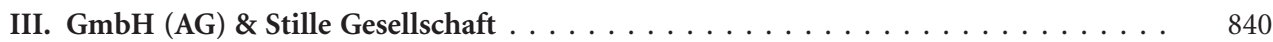

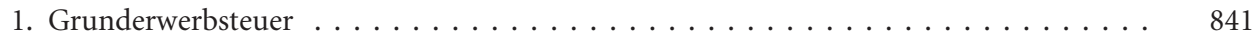

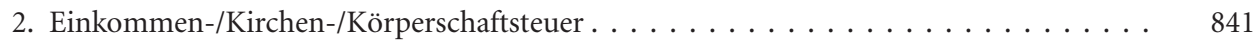

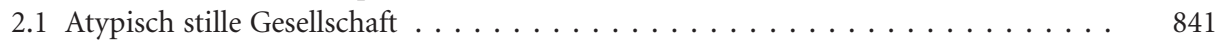

2.2 Typisch stille Gesellschaft . . . . . . . . . . . . . . . . . . . . . . 842

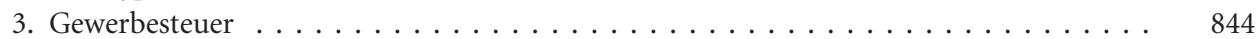

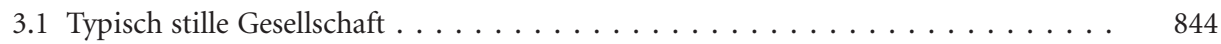

3.2 Atypisch stille Gesellschaft . . . . . . . . . . . . . . . . 844

C. Internationales und Europäisches Unternehmensteuerrecht . . . . . . . . . 844

I. Grundzüge der Besteuerung grenzüberschreitender Unternehmenstätigkeit . . . . . 844

1. Rechtsformabhängige Zuweisung von Besteuerungsrechten im Internationalen

2. Auslandsinvestitionen von Steuerinländern (Outbound-Sachverhalte) . . . . . . . . . 846

3. Inlandsinvestitionen von Steuerausländern (Inbound-Sachverhalte) . . . . . . . . . 847

II. Der Einfluss des Europarechts auf die Besteuerung von Unternehmen . . . . . . . . 848

1. Harmonisierung der Unternehmensbesteuerung . . . . . . . . . . . . . . 848

2. Überprüfung des nationalen Unternehmensteuerrechts am Maßstab der Grundfreiheiten durch den EuGH . . . . . . . . . . . . . . . . . 850

D. Rechtsformneutralität der Unternehmensbesteuerung . . . . . . . . . 854

1. Ursachen fehlender Rechtsformneutralität . . . . . . . . . . . . . . . 855

2. Verfassungs- und europarechtliche Dimension des Gebots der Rechtsformneutralität . . 855

3. Methoden zur Verwirklichung von Rechtsformneutralität und ihre Umsetzung in der Unternehmensteuerreform $2008 \ldots \ldots \ldots \ldots$. . . . . . 858

\section{$\S 14$ Konzern- und Umwandlungssteuerrecht}

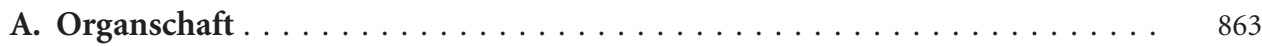

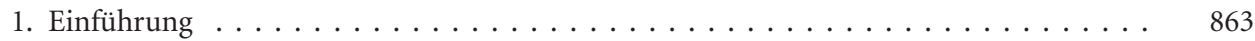

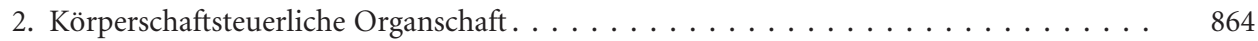

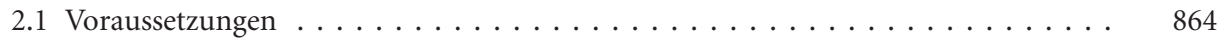

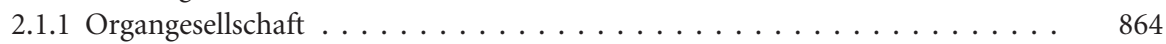

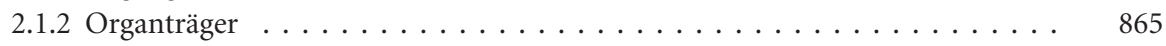


2.1.3 Finanzielle Eingliederung. . . . . . . . . . . . . . . . . . . . . . 866

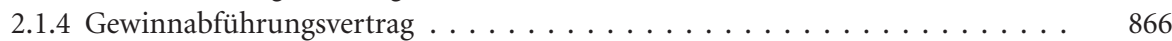

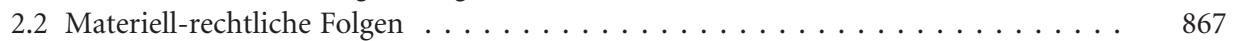

2.2.1 Grundsätze . . . . . . . . . . . . . . . . . . . . . . . . . . . . . . 867

2.2.2 Besonderheiten . . . . . . . . . . . . . . . . . . . . . . . 868

2.2.2.1 Verlustausgleichsverbot nach $\$ 14$ I 1 Nr. 5 KStG . . . . . . . . . 868

2.2.2.2 Vorvertragliche Rücklagen und Verluste . . . . . . . . . . . . . . 869

2.2.2.3 Bruttomethode nach $\$ 15$ Satz 1 Nr. 2 KStG . . . . . . . . . . . . . 869

2.2.2.4 Bruttomethode nach $\$ 15$ Satz 1 Nr. 3 KStG . . . . . . . . . . . . . 869

2.2.2.5 Thesaurierungsbegünstigung nach $\$ 34 \mathrm{a}$ EStG und Gewerbesteueranrechnung . . . . . . . . . . . . . . . . . . . . . 869

2.2.2.6 Ausgleichszahlungen nach $\$ 304 \mathrm{AktG} \ldots \ldots \ldots$. . . . . . . 870

2.2.2.7 Mehr- und Minderabführungen nach $\S 14$ III, IV KStG . . . . . . . . 870

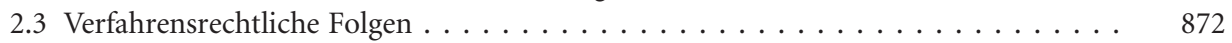

3. Gewerbesteuerliche Organschaft . . . . . . . . . . . . . . . . . . . . . . . 872

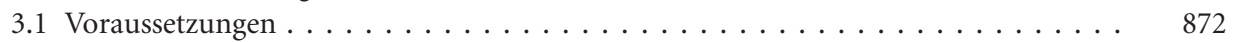

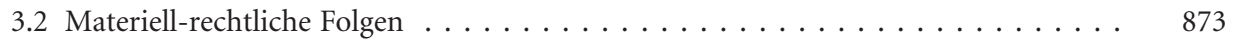

3.2 .1 Grundsätze . . . . . . . . . . . . . . . . . . . 873

3.2.2 Gesonderte Ermittlung und Zusammenrechnung bereinigter Gewerbeerträge . $\quad 873$

3.3 Verfahrensrechtliche Folgen . . . . . . . . . . . . . . . . . . . 874

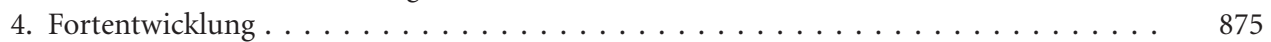

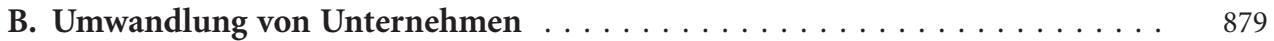

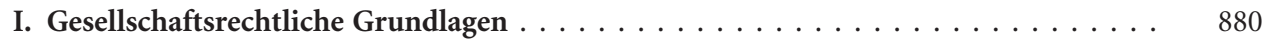

1. Umwandlungsgesetz . . . . . . . . . . . . . . . . . . . . . . . . 880

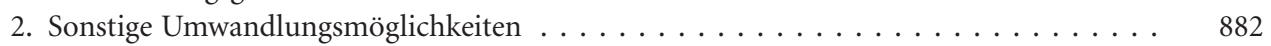

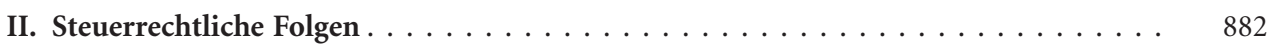

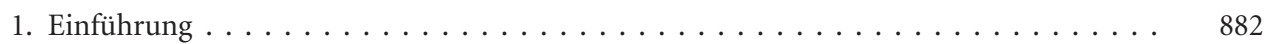

2. Umwandlungen im Inland . . . . . . . . . . . . . . . . . . . . 884

2.1 Vermögensübergang auf eine Personengesellschaft oder eine natürliche Person

$(\$ \$ 3-10 \mathrm{UmwStG}) \ldots \ldots \ldots$. . . . . . . . . . . . . . . . . . . . . . . . . . 884

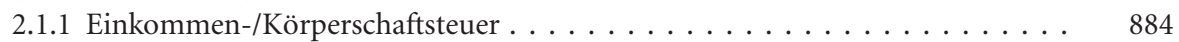

2.1.2 Gewerbesteuer . . . . . . . . . . . . . . . . . . . . . . . . . . 885

2.1.3 Grunderwerbsteuer . . . . . . . . . . . . . . . . . . . 886

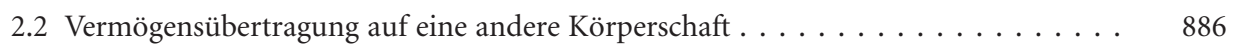

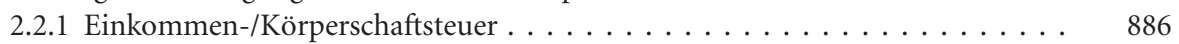

2.2.1.1 Grundsätze. . . . . . . . . . . . . . . . . . . 887

2.2.1.2 Zusätzliche Voraussetzungen und Restriktionen bei Spaltung und

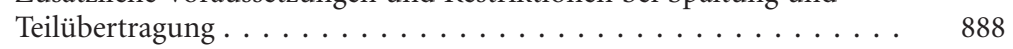

2.2 .2 Gewerbesteuer . . . . . . . . . . . . . . . . . . . . . 889

2.2 .3 Grunderwerbsteuer . . . . . . . . . . . . . . . . . . . . . . . 890

2.3 Einbringung eines Betriebs, Teilbetriebs oder Mitunternehmeranteils in eine Kapitalgesellschaft gegen Gewährung von Gesellschaftsanteilen ( $\$ \$ 20-23,25 \mathrm{UmwStG}$ ) . . .

2.3.1 Einkommen-/Körperschaftsteuer . . . . . . . . . . . . . . .

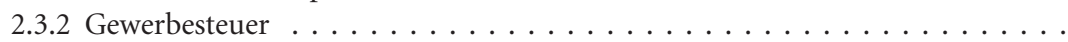

2.3.3 Grunderwerbsteuer . . . . . . . . . . . . . . . . . . . . 892 


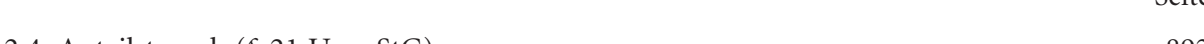

Anteilstausch $(\$ 21 \mathrm{UmwStG}) \ldots \ldots \ldots \ldots \ldots 2$

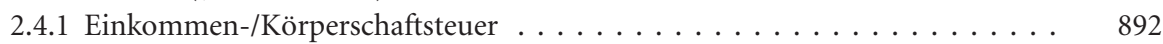

2.4 .2 Gewerbesteuer . . . . . . . . . . . . . . . . . . . . . . . . 892

2.4 .3 Grunderwerbsteuer . . . . . . . . . . . . . . . . . . . . 892

2.5 Einbringung eines Betriebs, Teilbetriebs oder Mitunternehmeranteils in eine

Personengesellschaft $(\$ 24 \mathrm{UmwStG}) \ldots \ldots \ldots \ldots \ldots$

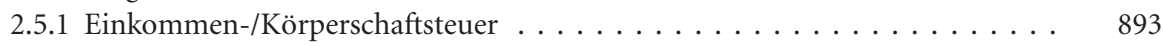

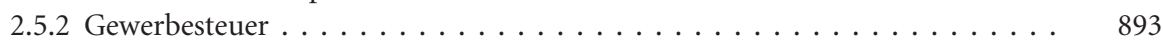

2.5 .3 Grunderwerbsteuer . . . . . . . . . . . . . . . . . . . . . . . . . . . . . . . . . . . . . . . .

3. Grenzüberschreitende und ausländische Umwandlungen . . . . . . . . . . . . . . . 893

\section{$\$ 15$ Erbschaft- und Schenkungsteuer}

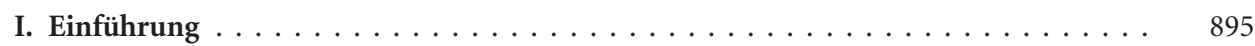

1. Rechtfertigung und Charakter der Erbschaft- und Schenkungsteuer . . . . . . . . . 895

2. Unveränderter Reformbedarf . . . . . . . . . . . . . . . . . 897

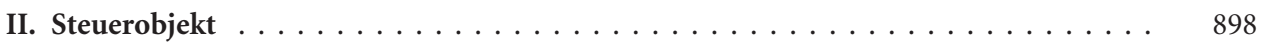

1. Erwerb von Todes wegen $(\$ \$ 1$ I Nr. $1 ; 3$ ErbStG $) \ldots \ldots \ldots \ldots \ldots \ldots \ldots$

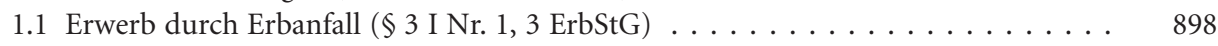

1.2 Erwerb auf Grund von Vermächtnis oder Pflichtteil . . . . . . . . . . . . 900

1.3 Erwerb durch Schenkung auf den Todesfall $(\$ 3$ I Nr. 2 ErbStG) . . . . . . . . . . 901

1.4 Erwerb durch Vertrag zugunsten Dritter auf den Todesfall (\$ 3 I Nr. 4 ErbStG) . . . 902

1.5 Erweiterung um Ergänzungs- und Ersatztatbestände $(\$ 3 \mathrm{II}$ ErbStG) . . . . . . . . . 902

2. Schenkung unter Lebenden $(\$ \$ 1$ I Nr. $2 ; 7$ ErbStG) . . . . . . . . . . . . . . . . 904

2.1 Grundtatbestand der freigebigen Zuwendung unter Lebenden ( $\$ 7$ I Nr. 1 ErbStG) 904

2.2 Gemischte Schenkung/Schenkung unter Auflage . . . . . . . . . . . . . . . . . . . 906

2.3 Mittelbare Schenkung . . . . . . . . . . . . . . . . . . . 907

2.4 Erweiterung um Ergänzungs- und Ersatztatbestände ( $\$ 7$ I Nr. 2-10, V-VII ErbStG) 908

3. Zweckzuwendung ( $\$ \$ 1$ I Nr. 3; 8 ErbStG) . . . . . . . . . . . . . . . . . 909

4. Ersatzerbschaftsteuer bei Familienstiftungen und -vereinen ( $\$ 1$ I Nr. 4 ErbStG) . . . . 909

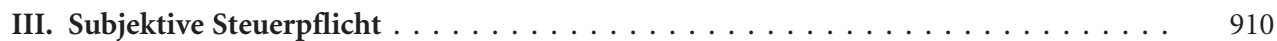

1. Steuersubjekte. . . . . . . . . . . . . . . . . . . . . . 910

1.1 Kreis der Steuerschuldner $(\$ 20 \mathrm{I}$ ErbStG $) \ldots \ldots \ldots \ldots \ldots \ldots$

1.2 Steuersubjektivität von Gesellschaften . . . . . . . . . . . . . . . 911

2. Steuerschuldnerschaft und spezielle Haftungstatbestände . . . . . . . . . . . . . . . 912

3. Internationale Abgrenzung der Steuerpflicht/Unionsrecht . . . . . . . . . . . 912

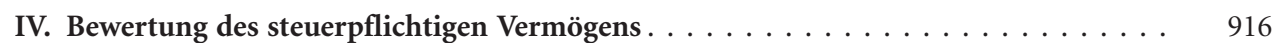

1. Bedarfsbewertung, Verfahren . . . . . . . . . . . . . . . . . . . . . 916

2. Spannungsverhältnis Verkehrswert/Ertragswert . . . . . . . . . . . . . . . 917

3. Verkehrswert als leitender Bewertungsmaßstab des Erbschaftsteuerrechts . . . . . . . . . 919

4. Bewertung des Grundvermögens und der Betriebsgrundstücke . . . . . . . . . . 920

4.1 Unbebaute Grundstücke . . . . . . . . . . . . . . . . . . . . . . 920

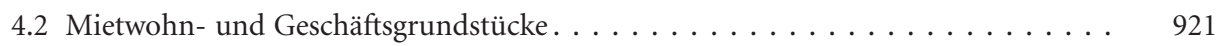

4.3 Ein- und Zweifamilienhäuser, Wohn- und Teileigentum . . . . . . . . . . 922 
4.4 Sachwertverfahren als Auffang-Bewertungsmethode . . . . . . . . . . . . 922

4.5 Erbbaurechte/Gebäude auf fremdem Grund und Boden . . . . . . . . . . . . . . 923

4.6 Nachweis des niedrigeren gemeinen Werts . . . . . . . . . . . . . . . 923

5. Bewertung land- und forstwirtschaftlichen Vermögens ( $\$ 158-175$ BewG) . . . . . . 923

6. Bewertung des Betriebsvermögens ( $\$ \$ 95-109 ; 199-203$ BewG) . . . . . . . . . . . 924

6.1 Ansatz und Zurechnung des Betriebsvermögens . . . . . . . . . . . . . . 925

6.2 Erforderlichkeit einer Unternehmensbewertung . . . . . . . . . . . . . 925

7. Bewertung sonstigen Vermögens _. . . . . . . . . . . . . . . . . . . 929

7.1 Geldvermögen, Wertpapiere, Kapitalforderungen, Schulden u. Ä. . . . . . . . . . 929

7.2 Anteile an nichtnotierten Kapitalgesellschaften . . . . . . . . . . . . . . . . 929

V. Steuerbefreiungen . . . . . . . . . . . . . . . . . . . . . . . . . . 929

1. Persönliche Freibeträge $(\$ 16$ i.V.m. $\$ 15$ ErbStG $) \ldots \ldots \ldots \ldots \ldots$

2. Besonderer Versorgungsfreibetrag $(\$ 17$ ErbStG $) \ldots \ldots \ldots \ldots \ldots \ldots \ldots \ldots \ldots$

3. Sachliche Steuerbefreiungen . . . . . . . . . . . . . . . . . 932

3.1 Verschonung des Unternehmensvermögens $(\$ \$ 13 \mathrm{a}-\mathrm{c}$ ErbStG $) \ldots \ldots \ldots . \ldots \ldots 2$

3.2 Verschonungsabschlag für zu Wohnzwecken vermietete Grundstücke

(\$13d ErbStG n.F.) . . . . . . . . . . . . . . . . . . . . . . . . . 940

3.3 Zuwendungen im Ehe- und Familienkreis ( $\$ 13$ I Nr. 4a, 4b, 4c ErbStG) . . . . . 941

3.4 Sonstige sachliche Steuerbefreiungen . . . . . . . . . . . . . . . . 943

VI. Steuerbemessungsgrundlage . . . . . . . . . . . . . . . . . . . . 944

VII. Entstehung der Steuer, Bewertungsstichtag $\ldots \ldots \ldots \ldots \ldots \ldots \ldots \ldots$

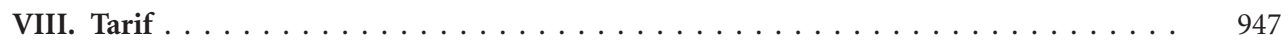

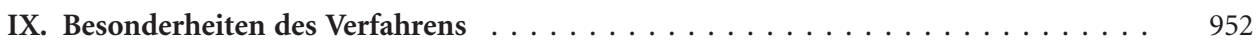

1. Anzeigepflichten . . . . . . . . . . . . . . . . . . . . . . . 952

2. Steuererklärungspflichten . . . . . . . . . . . . . . . . . . . . . . 953

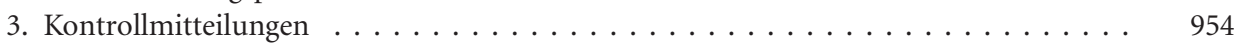

\section{$\$ 16$ Grund-/Vermögensteuer}

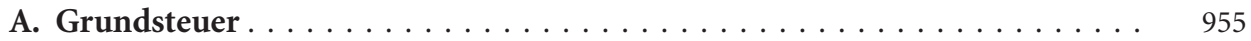

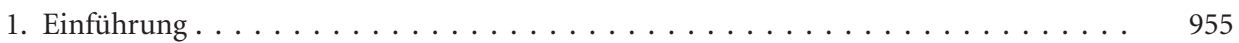

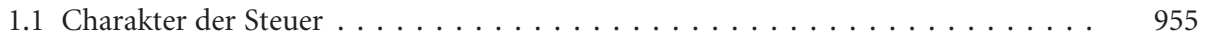

1.2 Rechtfertigung der Steuer . . . . . . . . . . . . . . . . . . . . . . . . 956

2. Steuerobjekt $(\$ 2 \mathrm{GrStG}) \ldots \ldots \ldots \ldots \ldots \ldots \ldots \ldots \ldots$

3. Einheitsbewertung des Grundbesitzes . . . . . . . . . . . . . . . . . 958

3.1 Bewertungsverfahren . . . . . . . . . . . . . . . . . 958

3.2 Einheitswert land- und forstwirtschaftlicher Betriebe ( $\$ \$ 19$ I; 33-67 BewG) . . . . 959

3.3 Einheitswert von Grundstücken (\$\$19 I; 68-94; 99 BewG) . . . . . . . . . . . . 959

3.4 Besonderheiten in den "neuen “ Bundesländern . . . . . . . . . . . . . . 962

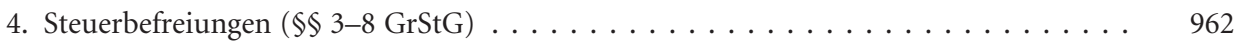

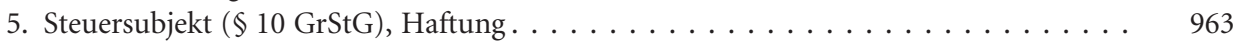

6. Steuermessbetrag $(\$ 13 \mathrm{GrStG}) \ldots \ldots \ldots \ldots \ldots \ldots \ldots \ldots$

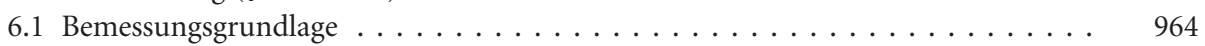

6.2 Steuermesszahl . . . . . . . . . . . . . . . . . . . 965 


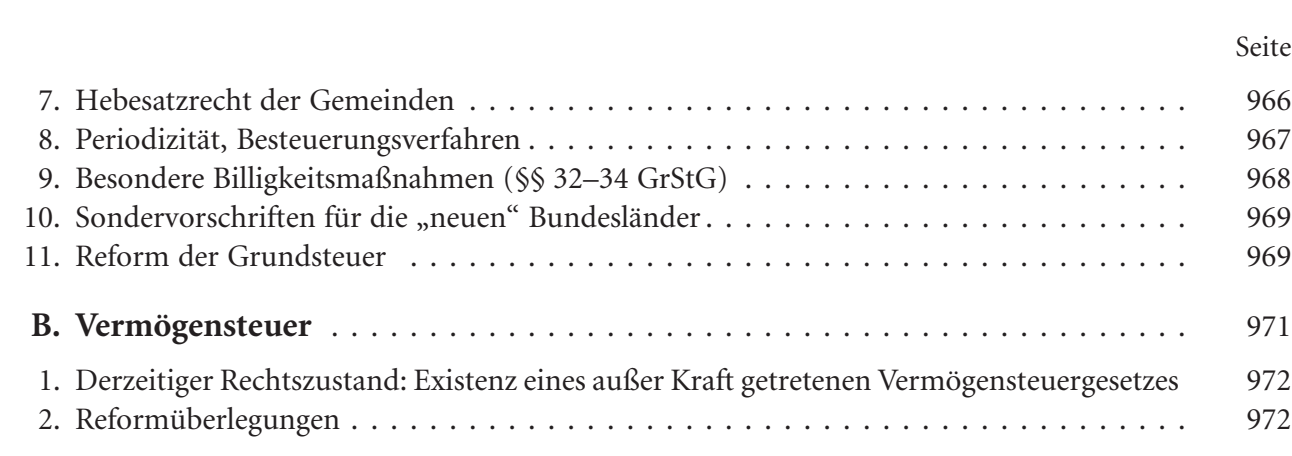

Seite

\section{$\$ 17$ Umsatzsteuer}

A. Entwicklung und System der Umsatzsteuer $\ldots \ldots \ldots \ldots \ldots \ldots$

1. Geschichtlicher Überblick . . . . . . . . . . . . . . . . . . . . . . . . . . . 976

2. Rechtsgrundlagen im nationalen und im Unionsrecht . . . . . . . . . . . . . . 977

3. Belastungsgrund und Belastungstechnik . . . . . . . . . . . . . . . . 980

3.1 Die Umsatzsteuer als indirekte Verbrauchsteuer . . . . . . . . . . . . . . . . 980

3.2 Die Umsatzsteuer als Allphasen-„,Mehrwertsteuer“ . . . . . . . . . . . . . . . . . 984

3.3 Die Umsatzsteuer als Verkehrsteuer . . . . . . . . . . . . . . . . . . . . 986

3.4 Neutralitätsprinzip und weitere zentrale Steuerprinzipien . . . . . . . . . . 987

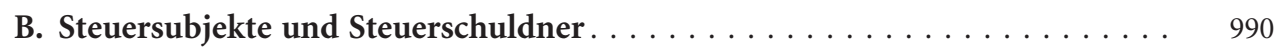

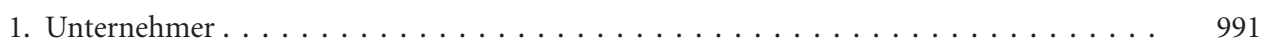

1.1 Abstrakte Unternehmerfähigkeit . . . . . . . . . . . . . . . . . . . . . . . . . . . . . . . . . 992

1.2 Selbständige Tätigkeit. . . . . . . . . . . . . . . . . . . . . . . . . . . . . . . . . . . . . . . . . . . . . . . . . . . .

1.3 Gewerbliche oder berufliche Tätigkeit . . . . . . . . . . . . . . . . . . . . . . . . 996

1.4 Beginn und Ende der Unternehmereigenschaft . . . . . . . . . . . . . . . . . . . . . . . . . . . . . . . . . . . . . . . . . . . . . . .

1.5 Unternehmenseinheit . . . . . . . . . . . . . . . . . . . . . . . . . . 1000

1.6 Unternehmereigenschaft von juristischen Personen des öffentlichen Rechts . . . . . 1000

1.7 Organschaftliche Unternehmensverbindungen . . . . . . . . . . . . . . . . . . . . 1004

1.8 Nur im Interesse der Mitglieder tätige Vereinigungen . . . . . . . . . . . . . . . . . . 1009

1.9 Kleinunternehmer . . . . . . . . . . . . . . . . . . . . . . . . . . . 1010

2. Ausnahmen: Nichtunternehmer als Steuersubjekte und Steuerschuldner . . . . . . . . 1012

3. Verlagerung der Steuerschuldnerschaft auf den Leistungsempfänger . . . . . . . . . . . . 1012

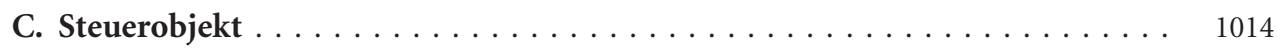

1. Entgeltliche Leistungen von Unternehmern im Inland ( $\$ 1$ I Nr. 1 UStG) . . . . . . . . 1014

1.1 Leistungen (Lieferungen und sonstige Leistungen) . . . . . . . . . . . . . . . . . . . . . . . . . . . . . . . . . . . . . . . . . . . . .

1.1 .1 Lieferungen . . . . . . . . . . . . . . . . . . . . . . . . . . . . . . . . . . . . . . . . . . . . . . . . .

1.1.1.1 Begriff, Grundformen . . . . . . . . . . . . . . . . . . . . . . . . . . . . . . . . . . . . . . . . . . . .

1.1 .1 .2 Sonderregeln . . . . . . . . . . . . . . . . . . . . . . . . . . 1022

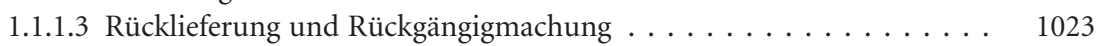

1.1.2 Sonstige Leistungen . . . . . . . . . . . . . . . . . . . . . . . . . . . . . . . . . . . . . . . . . . . . . . . . . . . . . . . . .

1.1 .3 Regeln für gemischte Leistungen . . . . . . . . . . . . . . . . . . . . . 1026

1.1.4 Sonderbestimmungen zum Leistungsgegenstand kraft wirtschaftlicher 
1.2 Zurechnung der Leistung zum Unternehmer . . . . . . . . . . . . . . . . 1031

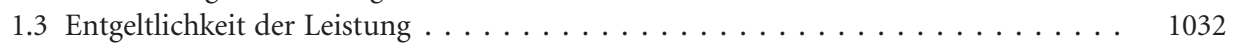

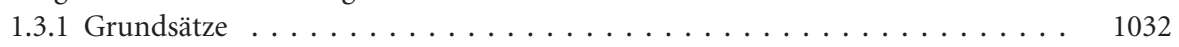

1.3.2 Tauschumsätze . . . . . . . . . . . . . . . . . . . . . . . . . . 1034

1.3.3 Einzelfälle zum Leistungsaustausch . . . . . . . . . . . . . . . . . . 1035

1.3.3.1 Erbschaft/Erbauseinandersetzung/vorweggenommene Erbfolge . . . . 1036

1.3.3.2 Schadensersatz . . . . . . . . . . . . . . . . . . . . 1037

1.3.3.3 Mitgliedsbeiträge an Vereine . . . . . . . . . . . . . . . . . . . . . 1040

1.3.3.4 Gesellschafterbeiträge . . . . . . . . . . . . . . . . . . . . 1041

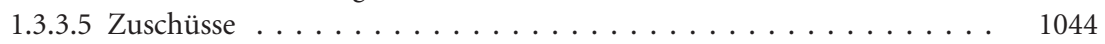

1.4 Leistungen im Rahmen des Unternehmens . . . . . . . . . . . . . . . . . . . . 1046

1.5 Inländischer Leistungsort . . . . . . . . . . . . . . . . . . . . . . . . 1048

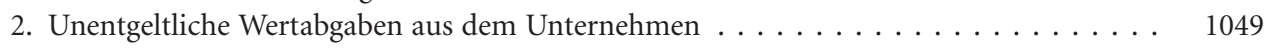

2.1 Grundsätze . . . . . . . . . . . . . . . . . . . . . . . . . . . . . 1049

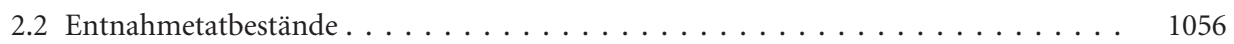

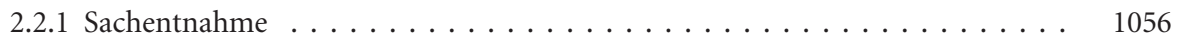

2.2 .2 Verwendungsentnahme . . . . . . . . . . . . . . . . . . . . . . . . . . . . . . . . 1058

2.2 .3 Leistungsentnahme . . . . . . . . . . . . . . . . . . . . . . . 1060

2.3 Unentgeltliche Wertabgaben an Arbeitnehmer . . . . . . . . . . . . . . . . . 1060

2.4 Unentgeltliche Sachzuwendungen an Dritte für Unternehmenszwecke . . . . . . . . . 1063

3. Nichtsteuerbarkeit der Geschäftsveräußerung . . . . . . . . . . . . . . . . . 1064

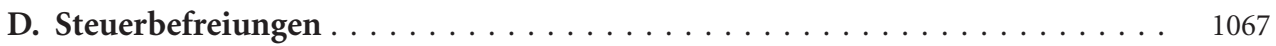

1. Rechtfertigung dem Grunde nach . . . . . . . . . . . . . . . . . . . . . . . . . . . . . . . . . . . . . . 1069

2. Versagung des Vorsteuerabzugs . . . . . . . . . . . . . . . . . . . . . 1071

3. Ausgewählte Befreiungstatbestände im Einzelnen . . . . . . . . . . . . . . . . . . 1074

3.1 Grundstücksüberlassungen . . . . . . . . . . . . . . . . . . . . 1074

3.2 Heilberufliche, soziale und kulturelle Leistungen . . . . . . . . . . . . . . . . . 1076

3.3 Finanzdienstleistungen . . . . . . . . . . . . . . . . . . . . . . . . . . 1079

3.4 Befreiungen wegen Konkurrenz zu besonderen Verkehrsteuern . . . . . . . . . . . 1081

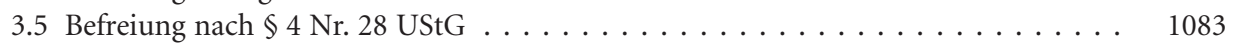

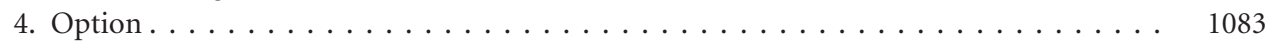

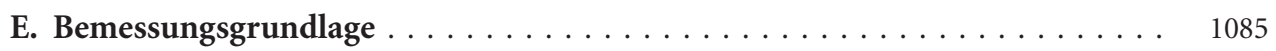

1. Entgelt beim Leistungsaustausch $\ldots \ldots \ldots \ldots \ldots \ldots \ldots \ldots \ldots \ldots$

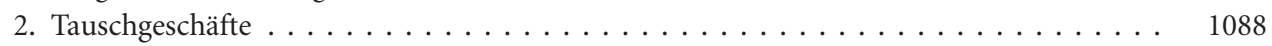

3. Unentgeltliche Wertabgaben . . . . . . . . . . . . . . . . . . . . . . . . 1089

4. Mindestbemessungsgrundlage . . . . . . . . . . . . . . . . . . . . . 1091

5. Innergemeinschaftlicher Erwerb und Einfuhr . . . . . . . . . . . . . . . . . 1092

6. Umsatzsteuer und Bemessungsgrundlage . . . . . . . . . . . . . . . . . . . . 1092

7. Differenz-(Margen-)besteuerung . . . . . . . . . . . . . . . . . . . 1093

F. Steuersätze . . . . . . . . . . . . . . . . . . . . . . . . . . 1095

1. Rechtfertigung von Steuerermäßigungen . . . . . . . . . . . . . . . . . . . . . . . . . . . . . . . . 1096

2. Einzelne Ermäßigungstatbestände . . . . . . . . . . . . . . . . . . . . . 1097 
G. Steuerentstehung und nachträgliche Änderungen . . . . . . . . . . . . . . . 1099

1. Dualismus von Soll- und Ist-Besteuerung beim Leistungsaustausch . . . . . . . . . . . . 1099

2. Korrekturen nach $₫ 17$ UStG . . . . . . . . . . . . . . . . . . . . . . . 1101

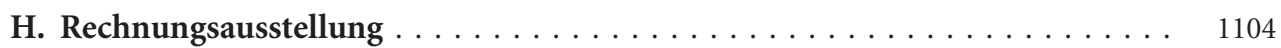

1. Allgemeines . . . . . . . . . . . . . . . . . . . . . . . . . . . . . 1104

2. Steuerschuld bei unrichtigem oder unberechtigtem Steuerausweis . . . . . . . . . 1106

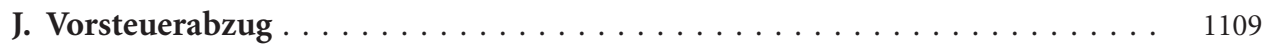

1. Einführung . . . . . . . . . . . . . . . . . . . . . . . . . . . 1109

2. Abzug der im zwischenunternehmerischen Leistungsaustausch abgerechneten Vorsteuer 1113

2.1 Leistung von einem anderen Unternehmer . . . . . . . . . . . . . . . . . . . . 1113

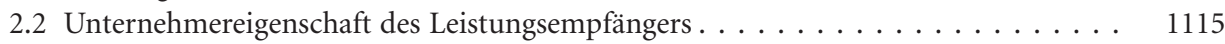

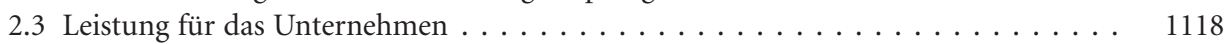

2.3.1 Grundsätzliche Erwägungen . . . . . . . . . . . . . . . . . . . . . 1118

2.3.2 Gemischte Verwendung und Zuordnungswahlrecht . . . . . . . . . . . . . . . 1124

2.4 Ordnungsgemäße Rechnung . . . . . . . . . . . . . . . . . . . . . . . . . . . 1129

3. Analoge Anwendung einkommensteuerlicher Abzugsverbote . . . . . . . . . . . . . . 1131

4. Ausschluss des Vorsteuerabzugs bei steuerfreien Umsätzen . . . . . . . . . . . . . . . 1131

4.1 Überblick . . . . . . . . . . . . . . . . . . . . . . . . . . . . . . . . . . . . . . . . . . . . . . . . . . . . .

4.2 Anteiliger Vorsteuerabzug bei gemischter Verwendung . . . . . . . . . . . . . . . 1135

K. Berichtigung des Vorsteuerabzugs nach $\$ 15$ a UStG $\ldots \ldots \ldots \ldots$

1. Überblick . . . . . . . . . . . . . . . . . . . . . . . . . . . . . . . . . . 1137

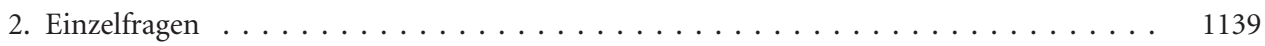

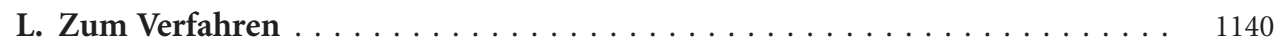

M. Sonderregelung für Land- und Forstwirte . . . . . . . . . . . . . . . . 1141

N. Grundzüge des Internationalen Umsatzsteuerrechts . . . . . . . . . . . 1142

1. Leitgedanken territorialer Zuordnung von Steuerhoheiten . . . . . . . . . . . . . . . 1142

2. Grundlagen des geltenden Regelungssystems in der EU . . . . . . . . . . . . . . . . . . . 1145

3. Zuordnung der Steuerhoheiten im Warenhandel . . . . . . . . . . . . . . . . . . . . 1147

3.1 Grundregeln zum Ort der Lieferung . . . . . . . . . . . . . . . . . . . . . . . . . . . . . . . . . . . . . . . . . . .

3.2 Grenzausgleich im Handel mit Drittstaatenbezug . . . . . . . . . . . . . . . . . . . . . . . . . . . . . . . . . . . . . . .

3.3 Handel innerhalb des EU-Binnenmarkts . . . . . . . . . . . . . . . . . . . . . . 1149

3.3 .1 Überblick . . . . . . . . . . . . . . . . . . . . . . . . . . . . . . . . 1149

3.3.2 Virtueller Grenzausgleich v.a. im zwischenunternehmerischen Handel . . . . . 1150

3.3.3 Handel mit Endverbrauchern und Gleichgestellten . . . . . . . . . . . . . . . . . . 1156

3.4 Reihengeschäfte . . . . . . . . . . . . . . . . . . . . . . . . . . . . . . . . . . . . . . . . . . . . . . . . . . .

3.5 Sonderregelungen für Energielieferungen . . . . . . . . . . . . . . . . . . . . . . . . . . 1162

4. Zuordnung der Steuerhoheiten bei sonstigen Leistungen . . . . . . . . . . . . . . . 1162

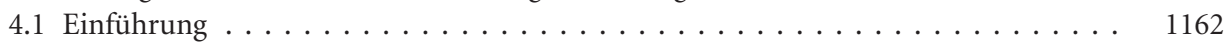

4.2 Grundregeln zum Ort der sonstigen Leistung . . . . . . . . . . . . . . . . . . . . . 1164

4.2.1 Leistung für unternehmerische und gleichgestellte Zwecke . . . . . . . . . . . . 1164 
4.2.2 Leistung für private Endverbraucher . . . . . . . . . . . . . . . . . . . . 1167

4.3 Überblick der speziellen Ortsregelungen . . . . . . . . . . . . . . . . . . . . 1167

5. Das innergemeinschaftliche Kontrollverfahren . . . . . . . . . . . . . . . . 1171

6. Perspektiven der Besteuerung grenzüberschreitender Leistungen im Binnenmarkt . . . 1172

O. Bekämpfung von Umsatzsteuerbetrug und -ausfällen . . . . . . . . . . . . 1174

\section{$\$ 18$ Spezielle Verkehr- und Verbrauchsteuern}

A. Grunderwerbsteuer . . . . . . . . . . . . . . . . . . . 1177

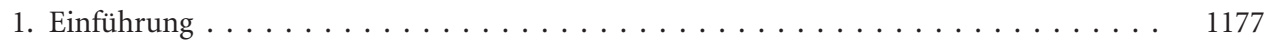

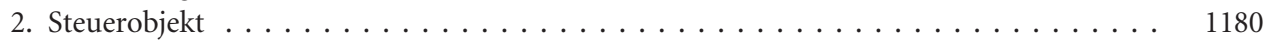

2.1 Eigentumswechsel an inländischem Grundstück (\$1 I GrEStG) $\ldots \ldots \ldots \ldots \ldots \ldots$

2.1.1 Eigentumserwerb und schuldrechtlicher Vertrag . . . . . . . . . . . . . . 1180

2.1.2 Kaufverträge und andere schuldrechtliche Verträge ( $\$ 1$ I Nr. 1 GrEStG) . . . 1181

2.1.3 Die Auflassung $(\$ 1$ I Nr. 2 GrEStG) . . . . . . . . . . . . . . . . . . . 1182

2.1.4 Der Eigentumserwerb $(\$ 1$ I Nr. 3 GrEStG $) \ldots \ldots \ldots \ldots \ldots \ldots$

2.1.5 Das Meistgebot $(\$ 1$ I Nr. 4 GrEStG $) \ldots \ldots \ldots \ldots \ldots \ldots$. . . . . . . . . . 1184

2.1.6 Abtretung von Übereignungsansprüchen und Rechten aus Kaufangeboten . . . 1184

2.2 Übergang der Verwertungsbefugnis . . . . . . . . . . . . . . . . . . . . 1185

2.3 Änderung im Gesellschafterbestand einer Personengesellschaft (\$1 IIa GrEStG) . . . 1185

2.4 Anteilsvereinigung. . . . . . . . . . . . . . . . . . . . . . . . 1189

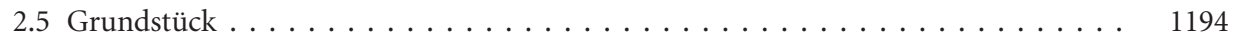

3. Befreiungen . . . . . . . . . . . . . . . . . . . . . . . . . . . . . . 1194

4. Steuersubjekte . . . . . . . . . . . . . . . . . . . . . . . . . . . 1199

5. Bemessungsgrundlage . . . . . . . . . . . . . . . . . . . . . . . . . . . 1199

5.1 Regel-Bemessungsgrundlage. . . . . . . . . . . . . . . . . . . . . . . 1199

5.2 Erwerb noch zu bebauender Grundstücke im Besonderen . . . . . . . . . . . . . 1201

5.3 Ansatz von Grundbesitzwerten . . . . . . . . . . . . . . . . . . . . . 1203

6. Steuersatz und Entstehung der Steuerschuld . . . . . . . . . . . . . . . . . . 1204

B. Versicherungsteuer . . . . . . . . . . . . . . . . . . . . . 1204

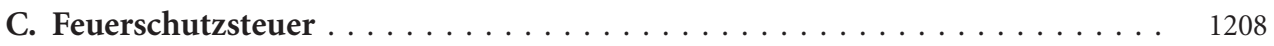

D. Rennwett- und Lotteriesteuer . . . . . . . . . . . . . . . . . . . . . . . . 1209

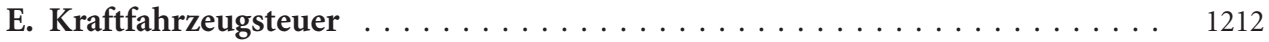

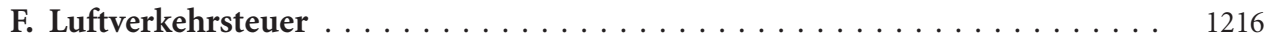

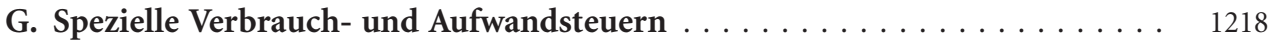

1. Überblick . . . . . . . . . . . . . . . . . . . . . . . . . . . . . . . . . . 1219

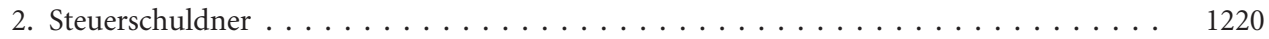

3. Steuerobjekte. . . . . . . . . . . . . . . . . . . . . . . . 1221

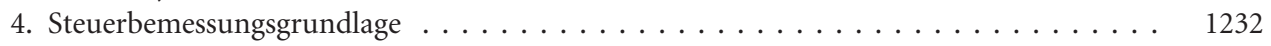

$\mathrm{XL}$ 


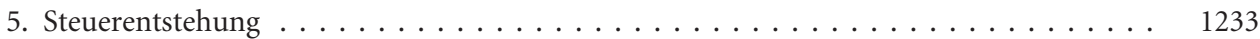

6. Verfahren ............................. 1233

\section{$\$ 19$ Arten und Rechtfertigung von Steuervergünstigungen}

A. Wirtschaftslenkende Steuervergünstigungen und Direktsubventionen . . . . 1235

B. Gesetze und Förderungszwecke wirtschaftslenkender Steuervergünstigungen und Direktsubventionen . . . . . . . . . . . . . . . . . . . . 1236

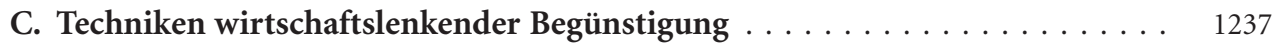

1. Entlastung durch wirtschaftslenkende Steuervergünstigungen $\ldots \ldots \ldots \ldots \ldots$. . . . 1238

1.1 Arten der Steuervergünstigung . . . . . . . . . . . . . . . . . . . . . 1238

1.2 Wirkung und Eignung der Steuervergünstigungen . . . . . . . . . . . . . . . 1238

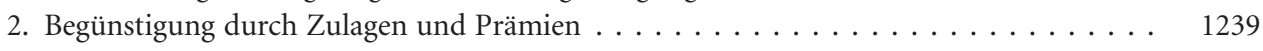

D. Rechtfertigung wirtschaftslenkender Normen . . . . . . . . . . . . . . . 1239

1. Allgemeine Rechtfertigung . . . . . . . . . . . . . . . . . . . . . . . . 1239

2. Verfassungsrechtliche Rechtfertigung . . . . . . . . . . . . . . . . . . . . . . . 1240

3. Vereinbarkeit mit Europarecht und Internationalen Abkommen . . . . . . . . . . . . . 1244

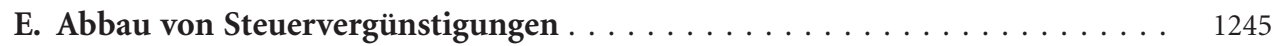

\section{$\S 20$ Gemeinnützigkeits- und Spendenrecht}

A. Gemeinnützigkeitsrecht . . . . . . . . . . . . . . . . . . . . . 1247

1. Gemeinnützigkeit als Förderung der Allgemeinheit . . . . . . . . . . . . . . . . . . 1247

2. Wirtschaftliche Betätigung gemeinnütziger Körperschaften . . . . . . . . . . . 1251

B. Spendenrecht . . . . . . . . . . . . . . . . . . . . . . . 1254

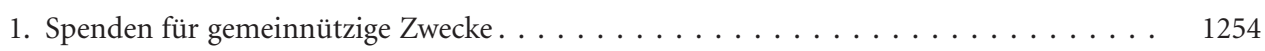

2. Spenden an politische Parteien . . . . . . . . . . . . . . . . . . . . 1257

3. Haftung und Vertrauensschutz bei Spendenbestätigung ( $\$ 10 \mathrm{~b}$ IV EStG; $\$ 9$ III KStG) . . 1257

\section{Steuerverfahrens- und Steuerstrafrecht}

\section{\$21 Durchführung der Besteuerung}

A. Prinzipien des Steuerverfahrens . . . . . . . . . . . . . . . . . . . . 1259

I. Gesetzmäßigkeit und Gleichmäßigkeit der Besteuerung . . . . . . . . . . . . . . . . 1259

1. Rechtsstaatlicher Auftrag der Finanzbehörden . . . . . . . . . . . . . . . . . . . 1259

2. Verfahrensmaximen ............................. 1260

2.1 Untersuchungsmaxime . . . . . . . . . . . . . . . . . . . 1260 
Seite

2.2 Kooperationsmaxime . . . . . . . . . . . . . . . . . . . . . 1261

3. Kontrollierte Selbstregulierung des Steuervollzugs . . . . . . . . . . . . . . . 1262

II. Übermaßverbot als Schranke der Sachaufklärung . . . . . . . . . . . . . . . . . . . 1263

III. Recht auf Informationsteilhabe, Grundsatz rechtlichen Gehörs . . . . . . . . . . . . 1264

IV. Vertrauensschutzprinzip; Grundsatz von Treu und Glauben . . . . . . . . . . . 1266

1. Verfassungsrechtliche Grundlagen des Vertrauensschutzes . . . . . . . . . . . . . 1266

2. Zusammenhang zwischen Vertrauensschutz und allgemeinem Rechtsgrundsatz von Treu und Glauben . . . . . . . . . . . . . . . . . . . . . . . . . . 1267

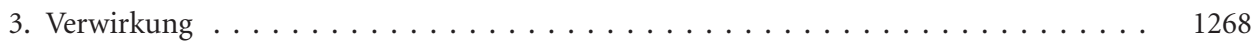

V. Datenschutz im Besteuerungsverfahren . . . . . . . . . . . . . . . . . . . . 1269

1. Recht auf informationelle Selbstbestimmung/EU-DSGVO v. 27.4.2016 . . . . . . . . 1269

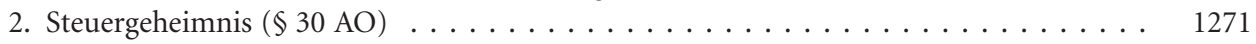

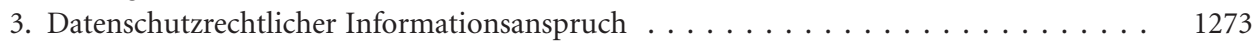

B. Organisation und Zuständigkeit der Finanzbehörden . . . . . . . . . . . 1275

I. Die Hierarchie der Finanzbehörden . . . . . . . . . . . . . . . . . . . . 1275

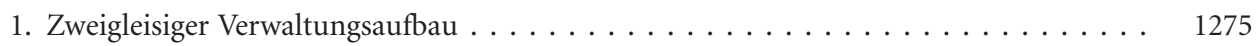

2. Weisungsrechte . . . . . . . . . . . . . . . . . . . . 1276

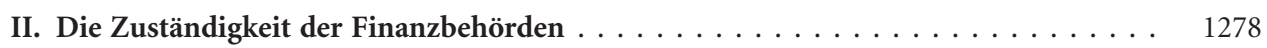

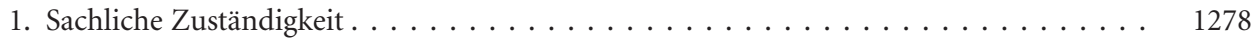

2. Örtliche Zuständigkeit . . . . . . . . . . . . . . . . . . . . . . . 1279

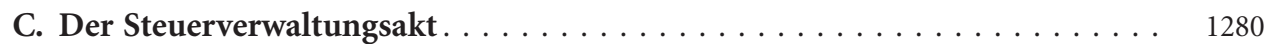

I. Bedeutung des Verwaltungsakts für das Besteuerungsverfahren $\ldots \ldots \ldots \ldots \ldots \ldots$

II. Begriff und Typologie des Verwaltungsakts _ . . . . . . . . . . . . . . . . . . 1281

1. Abgrenzung des Verwaltungsakts von anderen Handlungsformen . . . . . . . . . . . 1281

2. Typologie der Verwaltungsakte . . . . . . . . . . . . . . . . . . . . 1283

III. Entstehung des Steuerverwaltungsakts _ . . . . . . . . . . . . . . . . . . . 1284

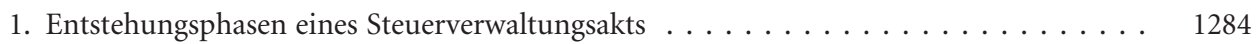

2. Wirksamwerden des Steuerverwaltungsakts . . . . . . . . . . . . . . . . . 1284

2.1 Geltung der Erklärungstheorie . . . . . . . . . . . . . . . . . . . . . . 1284

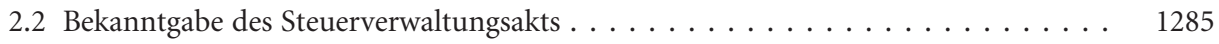

2.2.1 Zeitpunkt der Bekanntgabe . . . . . . . . . . . . . . . . . . . . 1285

2.2.2 Inhalts- und Bekanntgabeadressat . . . . . . . . . . . . . . . 1286

2.3 Fehler bei der Bekanntgabe des Steuerverwaltungsakts und deren Rechtsfolgen . . . 1288

IV. Bestandskraft des Steuerverwaltungsakts . . . . . . . . . . . . . . . . . . . . . 1289

1. Formelle und materielle Bestandskraft . . . . . . . . . . . . . . . . . . . . . 1289

2. Grundlagen- und Folgebescheide . . . . . . . . . . . . . . . . . . . . 1290

V. Anforderungen an die Ausgestaltung des Steuerverwaltungsakts . . . . . . . . . 1291

1. Inhaltliche Bestimmtheit . . . . . . . . . . . . . . . . . . . . . . . . 1291

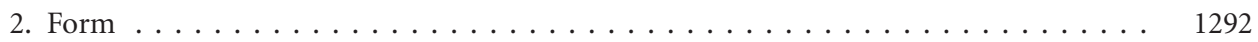

3. Begründung . . . . . . . . . . . . . . . . . . . . . . . . 1292 
Seite

VI. Nebenbestimmungen . . . . . . . . . . . . . . . . . . . . . . . . . . . . . . . . . . . . 1293

VII. Rechtswidrigkeit des Steuerverwaltungsakts . . . . . . . . . . . . . . . . . . 1295

VIII. Spezielle Steuerverwaltungsakte . . . . . . . . . . . . . . . . . . . . 1296

1. Steuerbescheid. . . . . . . . . . . . . . . . . . . . . . . . . . . 1296

2. Feststellungsbescheid . . . . . . . . . . . . . . . . . . . . . . . . . . 1297

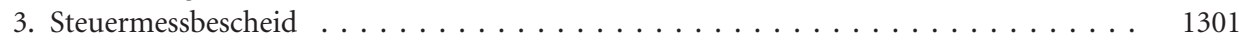

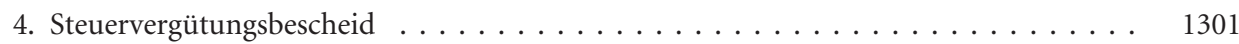

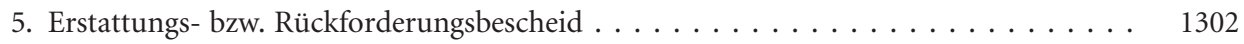

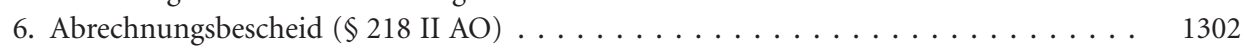

7. Haftungs- und Duldungsbescheid . . . . . . . . . . . . . . . . . 1303

D. Rechtsformen kooperativen Verwaltungshandelns . . . . . . . . . . . 1305

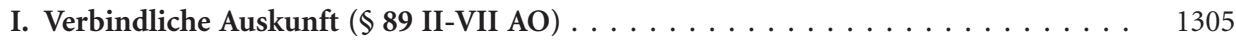

II. Lohnsteueranrufungsauskunft $(\$ 42 \mathrm{e} \mathrm{EStG)} \ldots \ldots \ldots \ldots \ldots \ldots \ldots$

III. Verbindliche Zusage nach einer Außenprüfung $(\$ \$ 204-207$ AO) . . . . . . . . . . . 1309

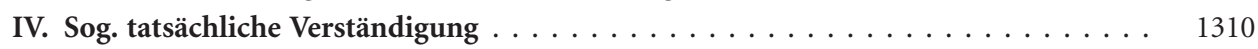

E. Verwaltungsverfahren im Steuerrecht $\ldots \ldots \ldots \ldots \ldots$. . . . . . . . . . 1314

I. Besteuerung im gestuften Verwaltungsverfahren . . . . . . . . . . . . . . . . 1314

II. Beteiligte des Besteuerungsverfahrens . . . . . . . . . . . . . . . . . . . 1314

1. Begriff des Beteiligten . . . . . . . . . . . . . . . . . . . . 1314

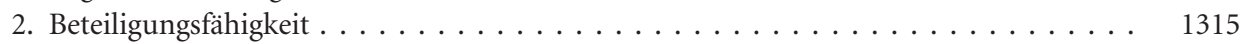

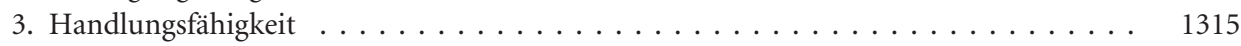

4. Bevollmächtigung (gewillkürte Vertretung) . . . . . . . . . . . . . . . 1316

F. Ermittlungsverfahren . . . . . . . . . . . . . . . . . . . . . . 1319

I. Letztverantwortung der Finanzbehörde für die Sachaufklärung . . . . . . . . . 1319

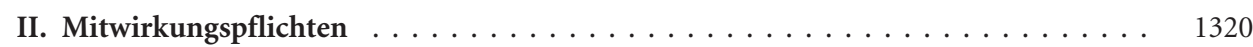

1. Allgemeiner Grundsatz $(\$ 90 \mathrm{AO}) \ldots \ldots \ldots \ldots \ldots \ldots \ldots$

2. Gesteigerte Mitwirkungspflicht bei Auslandssachverhalten . . . . . . . . . . . . . . . . . . . . . . . . . 1321

3. Anzeigepflichten nach $\$ \$ 137 \mathrm{ff}$. AO . . . . . . . . . . . . . . . . . . . . . . . . . 1322

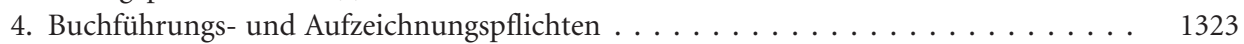

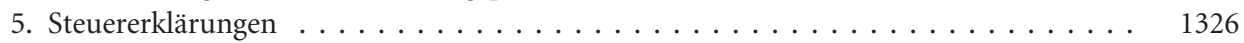

5.1 Verpflichtung zur Abgabe der Steuererklärung . . . . . . . . . . . . . . . . . . . . . 1326

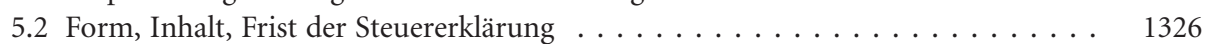

5.3 Verspätungszuschlag . . . . . . . . . . . . . . . . . . . . . . . . . 1329

5.4 Berichtigungspflicht bei unrichtigen Steuererklärungen . . . . . . . . . . . . 1330

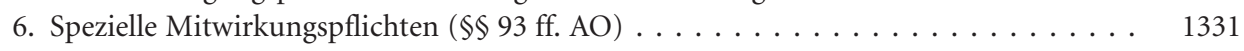

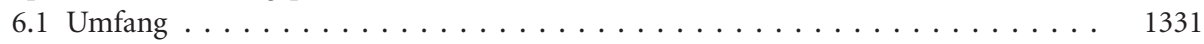

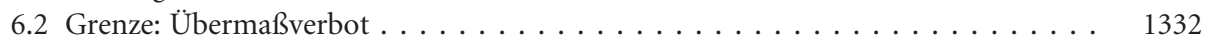

7. Mitwirkungsverweigerungsrechte . . . . . . . . . . . . . . . . 1333

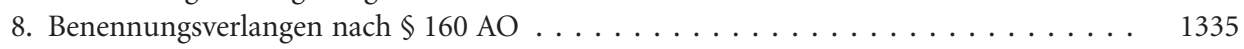

III. Beweis und Beweismaß in finanzbehördlichen Steuerverfahren . . . . . . . . . 1337

1. Gewissheitsgrad finanzbehördlicher Sachaufklärung . . . . . . . . . . . . 1337 
2. Beweisvermutung nach $\S 158$ AO, Vertrauensvorschussprinzip . . . . . . . . . . . . . . . 1337

3. Beweisreduzierung nach $₫ 162$ AO, Sphärenverantwortlichkeit . . . . . . . . . . 1338

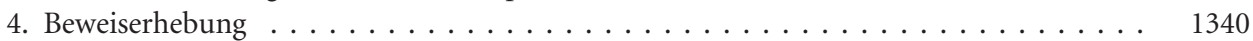

4.1 Beweisgegenstand und Beweismittel . . . . . . . . . . . . . . . . . 1340

4.2 Beweisverfahren . . . . . . . . . . . . . . . . . . . . . . . . . . . 1340

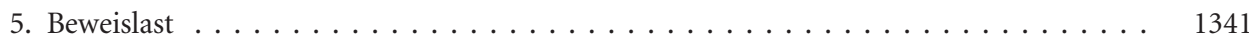

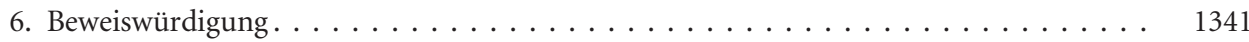

7. Beweisverwertungsverbote . . . . . . . . . . . . . . . . . . . . 1341

IV. Besondere Verfahren der Sachaufklärung . . . . . . . . . . . . . . . . . . . . . 1342

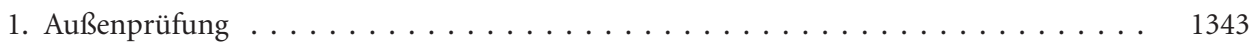

1.1 Zweck der Außenprüfung . . . . . . . . . . . . . . . . . . . . . . . 1343

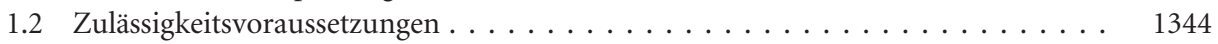

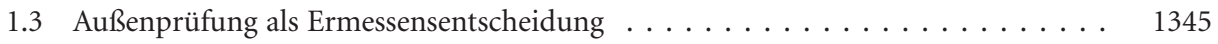

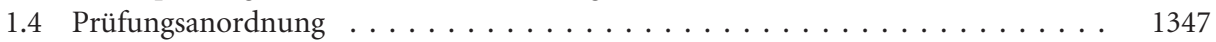

1.5 Prüfungsablauf . . . . . . . . . . . . . . . . . . . . . . . . . . . 1347

1.6 Digitale Außenprüfung. . . . . . . . . . . . . . . . . . . . . . . . . . . . 1349

1.7 Rechtliches Gehör, Schlussbesprechung . . . . . . . . . . . . . . . . . 1350

1.8 Verwertung der Prüfungsfeststellungen . . . . . . . . . . . . . . . . . 1351

1.9 Kontrollmitteilungen in der Außenprüfung . . . . . . . . . . . . . . . 1351

1.10 Besondere Arten von Außenprüfungen . . . . . . . . . . . . . . . . . . . . 1351

2. Steuerfahndung. . . . . . . . . . . . . . . . . . . . . 1352

3. Nachschau als besonderes Steueraufsichtsinstrument . . . . . . . . . . . . . 1354

V. Amtshilfe und Informationsaustausch $\ldots \ldots \ldots \ldots \ldots \ldots \ldots \ldots$

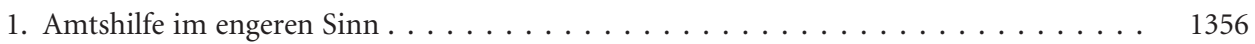

2. Sog. Spontanhilfe, Kontrollmitteilungen . . . . . . . . . . . . . . . . . . 1356

3. Internationaler Informationsaustausch . . . . . . . . . . . . . . . . . 1357

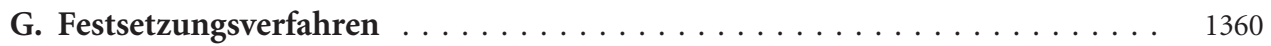

I. Arten der Steuerfestsetzung . . . . . . . . . . . . . . . . . . . . . . . . . 1360

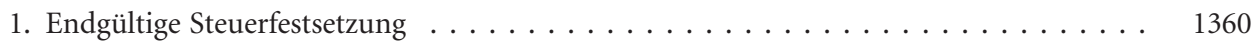

2. Vollautomatische Steuerfestsetzung $(\$ 155 \mathrm{IV} \mathrm{AO}) \ldots \ldots \ldots \ldots \ldots \ldots \ldots \ldots \ldots \ldots$

3. Steuerfestsetzung unter dem Vorbehalt der Nachprüfung . . . . . . . . . . . . . . . . 1361

4. Vorläufige Steuerfestsetzung, Aussetzung . . . . . . . . . . . . . . . . . . 1364

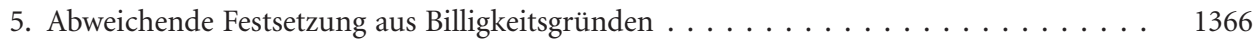

II. Festsetzungsverjährung . . . . . . . . . . . . . . . . . . . . . . . . . . . . . 1367

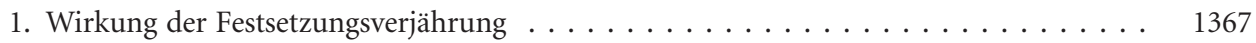

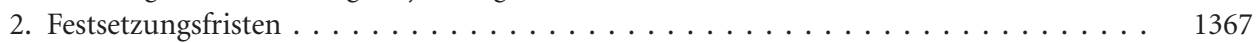

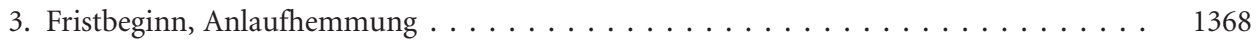

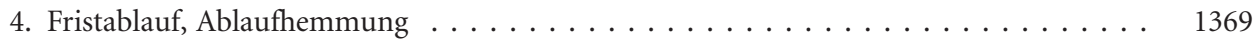

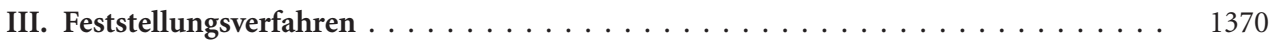

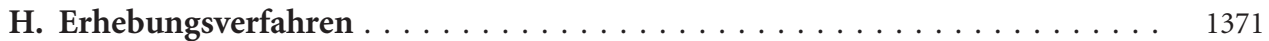

I. Verwaltungsakte mit Titelfunktion $(\$ 218$ I AO) als Grundlage für die Verwirk-
lichung von Ansprüchen aus dem Steuerschuldverhältnis $\ldots \ldots \ldots \ldots \ldots \ldots 1371$ 


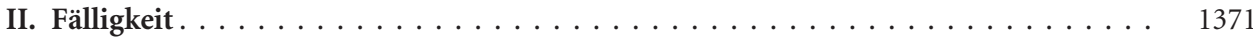

1. Grundsätze . . . . . . . . . . . . . . . . . . . . . . . . . . . . 1371

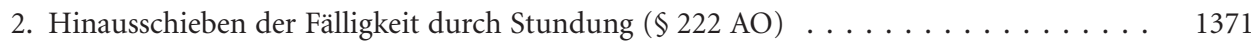

III. Erlöschen fälliger Ansprüche . . . . . . . . . . . . . . . . . . . . . . . 1373

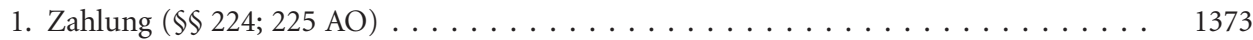

2. Aufrechnung $(\$ 226 \mathrm{AO}) \ldots \ldots \ldots \ldots \ldots \ldots \ldots \ldots$

3. Billigkeitserlass; Erstattung aus Billigkeitsgründen $(\$ 227$ AO $) \ldots \ldots \ldots$

3.1 Grundgedanke des Erlasses . . . . . . . . . . . . . . . . . . . . . . . . . 1375

3.2 Erlass als Ermessensentscheidung . . . . . . . . . . . . . . . . . . . . 1376

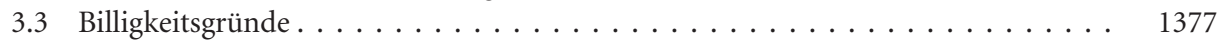

3.3 .1 Sachliche Unbilligkeit . . . . . . . . . . . . . . . . . . . . . . . . . . . . . . . . . . . . . . . . . . . . . . . . . . . . .

3.3.2 Persönliche Unbilligkeit . . . . . . . . . . . . . . . . . . . . . . . 1379

3.4 Billigkeitsmaßnahmen . . . . . . . . . . . . . . . . . . . . . . . . 1380

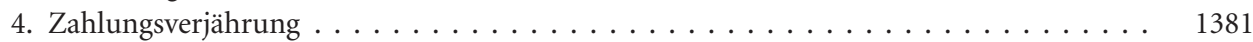

4.1 Verhältnis von Festsetzungs- und Zahlungsverjährung . . . . . . . . . . . . . . . . 1381

4.2 Verjährungsfrist, Hemmung, Unterbrechung . . . . . . . . . . . . . . . . . . 1381

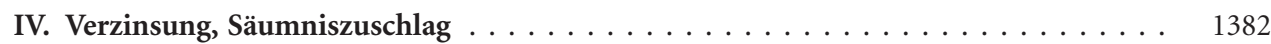

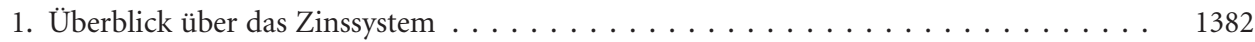

2. Die einzelnen Verzinsungstatbestände . . . . . . . . . . . . . . . . . . . . . . . . . 1384

2.1 Verzinsung von Steuernachforderungen und Steuererstattungen $(\$ 233 \mathrm{a}$ AO) $\ldots 1384$

2.2 Stundungszinsen $(\$ 234 \mathrm{AO}) \ldots \ldots \ldots \ldots \ldots \ldots \ldots$

2.3 Hinterziehungszinsen $(\$ 235 \mathrm{AO}) \ldots \ldots \ldots \ldots \ldots \ldots$

2.4 Prozesszinsen auf Erstattungsbeträge und Steuervergütungen $(\$ 236 \mathrm{AO}) \ldots \ldots$

2.5 Aussetzungszinsen $(\$ 237$ AO $) \ldots \ldots \ldots \ldots \ldots \ldots \ldots \ldots$

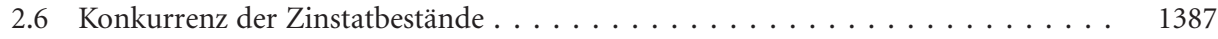

3. Zinsbescheid $(\$ 239 \mathrm{AO}) \ldots \ldots \ldots \ldots \ldots \ldots \ldots \ldots \ldots$

4. Säumniszuschlag $(\$ 240 \mathrm{AO}) \ldots \ldots \ldots \ldots \ldots \ldots \ldots \ldots \ldots$

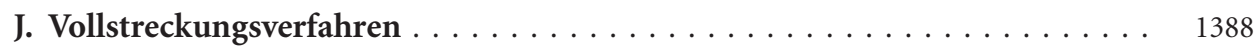

I. Besonderheit der Verwaltungsvollstreckung . . . . . . . . . . . . . . . . . . . . . . . 1388

II. Vollstreckung wegen Geldforderungen $(\$ \S 259-327$ AO) . . . . . . . . . . . . . . . . 1389

III. Vollstreckung wegen anderer Leistungen als Geldforderungen (Zwangsmittel,

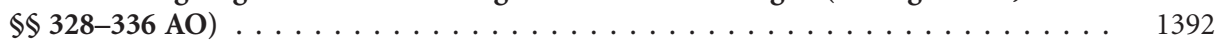

K. Korrektur von Steuerverwaltungsakten . . . . . . . . . . . . . . . . . . 1393

I. Zweigleisigkeit des Korrektursystems . . . . . . . . . . . . . . . . . . . . . . . 1393

II. Korrekturterminologie . . . . . . . . . . . . . . . . . . . . . . . . . . . . . 1394

III. Allgemeine Korrekturvorschriften . . . . . . . . . . . . . . . . . . . . . . . . . 1395

1. Berichtigung offenbarer Unrichtigkeiten $(\$ 129$ AO $) \ldots \ldots \ldots \ldots$

2. Sonstige allgemeine Korrekturvorschriften . . . . . . . . . . . . . . . . . . . . 1397

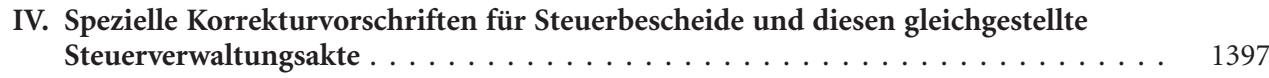

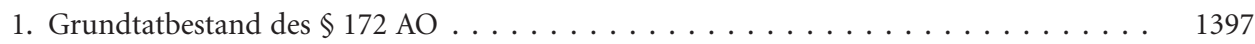


2. Korrektur wegen nachträglich bekannt werdender Tatsachen oder Beweismittel

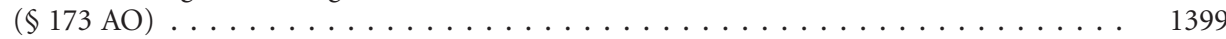

2.1 Grundgedanke der Vorschrift . . . . . . . . . . . . . . . . . . . . . . 1399

2.2 Die Tatbestandsmerkmale der Vorschrift . . . . . . . . . . . . . . . . . . . . . . . 1399

2.2.1 Tatsachen oder Beweismittel . . . . . . . . . . . . . . . . . . . . . . . . 1399

2.2.2 Nachträgliches Bekanntwerden . . . . . . . . . . . . . . . . . . . . 1400

2.2.3 Rechtserheblichkeit . . . . . . . . . . . . . . . . . . . . . 1401

2.2.4 Negativmerkmale: Ermittlungspflichtverletzung und grobes Verschulden . . . . 1402

2.2.5 Negativmerkmal: Änderungssperre nach $\$ 173$ II AO . . . . . . . . . . . . . 1403

3. Korrektur wegen bei Erstellung der Steuererklärung unterlaufenen Schreib- oder Rechenfehlern $(\$ 173 \mathrm{a} A O) \ldots \ldots \ldots \ldots \ldots \ldots \ldots$

4. Korrektur wegen widerstreitender Steuerfestsetzung $(\$ 174$ AO $) \ldots \ldots \ldots \ldots \ldots \ldots$

4.1 Mehrfachberücksichtigung eines Sachverhaltes $(\$ 174$ I, II AO) $\ldots \ldots \ldots \ldots \ldots \ldots$

4.2 Nichtberücksichtigung eines Sachverhalts $(\$ 174$ III AO) $\ldots \ldots \ldots \ldots \ldots \ldots$

4.3 Folgekorrektur nach $\$ 174$ IV, V AO . . . . . . . . . . . . . . . . . . . . 1407

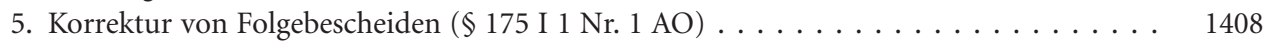

6. Korrektur wegen rückwirkenden Ereignisses $(\$ 175$ I 1 Nr. 2 AO) $\ldots \ldots \ldots \ldots \ldots \ldots \ldots$

7. Korrektur bei Datenübermittlung durch Dritte $(\$ 175 b$ AO $) \ldots \ldots \ldots \ldots \ldots \ldots \ldots . \ldots 1412$

8. Unselbständige Korrektur von materiellen Fehlern $(\$ 177$ AO $) \ldots \ldots \ldots \ldots \ldots \ldots \ldots$.

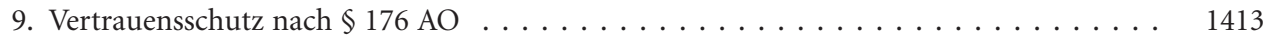

V. Korrekturvorschriften für andere Steuerverwaltungsakte . . . . . . . . . . . . . 1415

1. Überblick über die Regeln der $\$ \$ 130 ; 131$ AO . . . . . . . . . . . . . . . . . . . . . . . 1415

2. Rücknahme eines rechtswidrigen Steuerverwaltungsakts $(\$ 130 \mathrm{AO}) \ldots \ldots \ldots \ldots \ldots$

2.1 Rücknahme eines belastenden Steuerverwaltungsakts (\$130 I AO) . . . . . . . . . 1416

2.2 Rücknahme eines begünstigenden Steuerverwaltungsakts (\$130 II AO) . . . . . . . 1416

3. Widerruf eines rechtmäßigen Steuerverwaltungsakts $(\$ 131$ AO) $\ldots \ldots \ldots \ldots \ldots \ldots$

3.1 Widerruf eines belastenden Steuerverwaltungsakts $(\$ 131$ I AO) $\ldots \ldots \ldots \ldots \ldots \ldots 1418$

3.2 Widerruf eines begünstigenden Steuerverwaltungsakts $(\$ 131$ II AO) . . . . . . . . 1418

\section{$\$ 22$ Rechtsschutz in Steuersachen}

A. Überblick über das Rechtsschutzsystem . . . . . . . . . . . . . . . . . . . . 1421

I. Der Justizgewährleistungsanspruch des Art. 19 IV GG . . . . . . . . . . . . . . . . 1421

II. Die verschiedenen Rechtswege . . . . . . . . . . . . . . . . . . . . . . . . . . 1423

B. Außergerichtliches Rechtsbehelfsverfahren . . . . . . . . . . . . . . 1423

I. Zweck und Rechtsnatur des Rechtsbehelfsverfahrens _ . . . . . . . . . . . . . . 1423

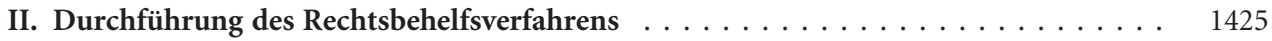

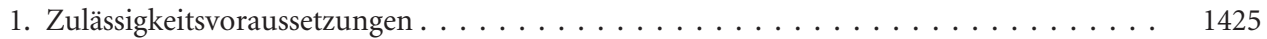

2. Eingeschränkter Suspensiveffekt des Einspruchs . . . . . . . . . . . . . . . . . 1428

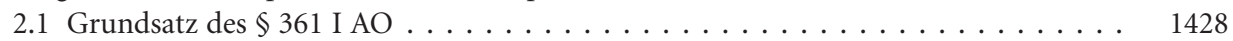

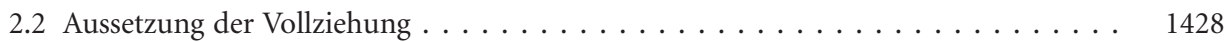

3. Hinzuziehung zum Verfahren $(\$ 360$ AO $) \ldots \ldots \ldots \ldots \ldots$. . . . . . . . . . . . . . . 1429

4. Die Ausgestaltung des Einspruchsverfahrens . . . . . . . . . . . . . . . . . . . . 1429 
Seite

4.1 Charakter eines verlängerten Verwaltungsverfahrens . . . . . . . . . . . . . . . . . . 1429

4.2 Rechtliches Gehör, Erörterung des Sach- und Rechtsstandes (\$ 364a AO) . . . . . . 1430

4.3 Präklusion verspäteten Tatsachenvortrages $(\$ 364 \mathrm{~b}$ AO $) \ldots \ldots \ldots$. . . . . . . . . . . . . . . . . . . . . . . . . .

4.4 Aussetzung und Ruhen des Verfahrens $(\$ 363$ AO $) \ldots \ldots \ldots \ldots$. . . . . . . . . . 1432

III. Abschluss des Rechtsbehelfsverfahrens . . . . . . . . . . . . . . . . . . . . . 1433

C. Gerichtliches Rechtsbehelfsverfahren . . . . . . . . . . . . . . . 1436

I. Die Gerichtsverfassung der Finanzgerichtsbarkeit . . . . . . . . . . . . . . . . 1436

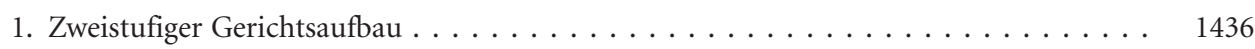

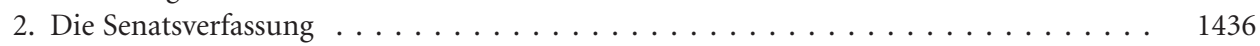

3. Der sog. fakultative Einzelrichter $(\$ 6 \mathrm{FGO}) \ldots \ldots \ldots \ldots \ldots \ldots$

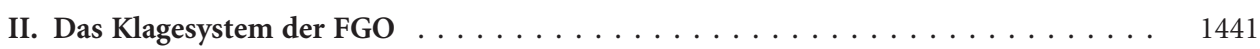

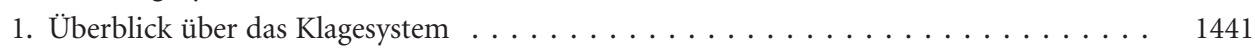

2. Die Klagearten im Einzelnen . . . . . . . . . . . . . . . . . . . . . . . . . . . . . . 1442

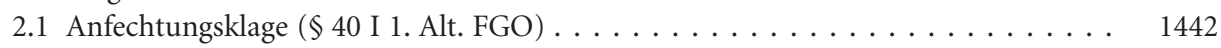

2.2 Verpflichtungsklage $(\$ 40$ I 2. Alt. FGO) . . . . . . . . . . . . . . . . . . . . . 1443

2.3 Sonstige (allgemeine) Leistungsklage ( $\$ 40$ I 3. Alt. FGO) . . . . . . . . . . . . . . . . . . . . . . . . . . . . . . . . . . . . . . . . .

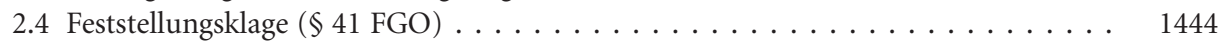

III. Zulässigkeit der Klage . . . . . . . . . . . . . . . . . . . . . . . . . . . . . . . 1445

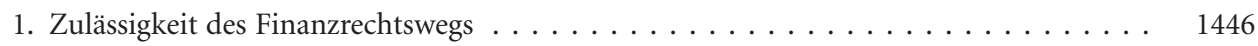

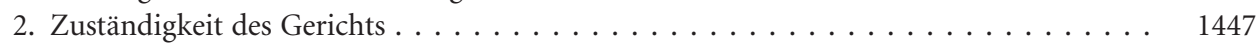

3. Statthafte Klageart . . . . . . . . . . . . . . . . . . . . . . . . . . . . . . . . . 1448

4. Erfolgloses Vorverfahren $(\$ 44 \mathrm{I}$ FGO $) \ldots \ldots \ldots \ldots \ldots \ldots \ldots$

4.1 Grundsatz des obligatorischen Vorverfahrens . . . . . . . . . . . . . . . . . . . . . . . . . . . . . . . . . . . . . . . . . . . .

4.2 Ausnahmen vom Vorverfahren . . . . . . . . . . . . . . . . . . . . . . . . . . . . . . . . . . . . . . . . . . . . . . . . . .

4.2 .1 Sog. „Untätigkeitsklage“ $(\$ 46 \mathrm{FGO}) \ldots \ldots \ldots \ldots \ldots \ldots$

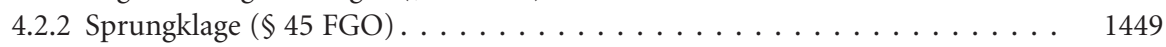

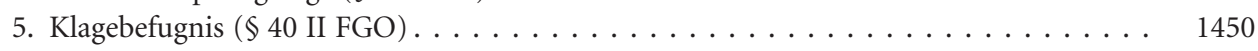

5.1 Anwendungsbereich und Funktion der Klagebefugnis . . . . . . . . . . . . . . . . . . . . . . . . . . . . . . . . . . . . . . . . . . . . . .

5.2 Rechtsverletzung . . . . . . . . . . . . . . . . . . . . . . . . . . . . . . . . . . . . . . . . . . . . . . . . . . . . . . . . . .

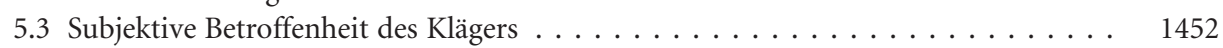

5.4 Vortrag zur Klagebefugnis („Geltendmachung") . . . . . . . . . . . . . . . . . . . 1454

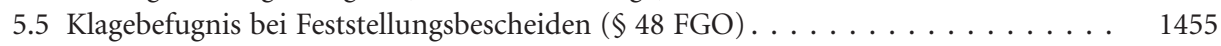

6. Beteiligten-, Prozess-, Postulationsfähigkeit . . . . . . . . . . . . . . . . . . . 1456

7. Wahrung der Klagefrist $(\$ 47 \mathrm{FGO}) \ldots \ldots \ldots \ldots \ldots \ldots \ldots \ldots$

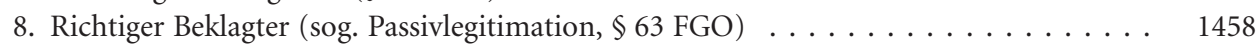

9. Ordnungsmäßigkeit der Klageerhebung $(\$ \$ 64 ; 65$ FGO $) \ldots \ldots \ldots \ldots$

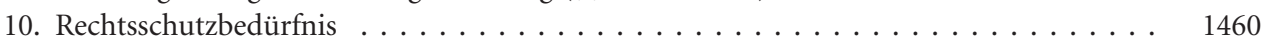

11. Negative Sachurteilsvoraussetzungen . . . . . . . . . . . . . . . . . . . . 1461

IV. Übersicht über die gerichtlichen Rechtsbehelfe . . . . . . . . . . . . . . . . . . . . . 1461

V. Das Klageverfahren . . . . . . . . . . . . . . . . . . . . . . . . . . . . . . . . 1462

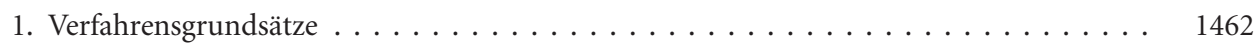

1.1 Untersuchungsgrundsatz . . . . . . . . . . . . . . . . . . . . . . . . . . . . . . . . . . . . . . . . . . . . . . . . . . .

1.2 Offizial- und Dispositionsmaxime . . . . . . . . . . . . . . . . . 1463 
1.3 Grundsat der Munthichkeit und Öffentlichkeit.................. Seite

1.4 Grundsatz rechtlichen Gehörs (Art. 103 I GG) . . . . . . . . . . . . . . . . . . . 1465

2. Beiladung $(\$ \$ 60 ; 60$ a FGO $) \ldots \ldots \ldots \ldots \ldots \ldots \ldots \ldots$

3. Sachaufklärung und Entscheidungsfindung durch das Gericht . . . . . . . . . . . . 1466

3.1 Überblick über die Stationen der Sachaufklärung . . . . . . . . . . . . . . . . . . . 1466

3.2 Vorbereitende Sachaufklärung . . . . . . . . . . . . . . . . . . . . 1467

3.3 Beweiserhebung . . . . . . . . . . . . . . . . . . . . . . 1469

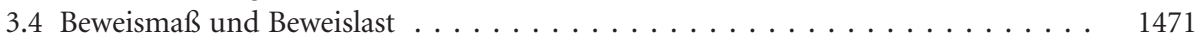

3.4.1 Regelbeweismaß . . . . . . . . . . . . . . . . . 1471

3.4.2 Beweismaßorientierung an der Sphärenverantwortlichkeit/fundamentale Beweisregeln . . . . . . . . . . . . . . . . . . . . . 1472

3.4.3 Beweislastorientierung an der Sphärenverantwortlichkeit . . . . . . . . . . . 1473

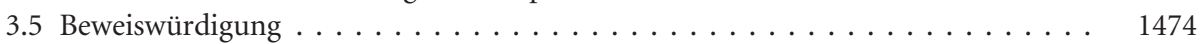

3.5.1 Grundsatz der freien Beweiswürdigung . . . . . . . . . . . . . . . . . . . . . . . . . . . . . . . . . . . . . . . . .

3.5.2 Indizien- und Anscheinsbeweis . . . . . . . . . . . . . . . . . . . . . . . . . . . . . . . . . . . 1475

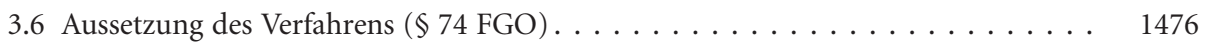

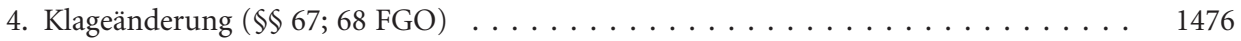

5. Entscheidung des Gerichts . . . . . . . . . . . . . . . . . . . . . 1477

5.1 Entscheidungsinhalt . . . . . . . . . . . . . . . . . . . . . 1477

5.2 Entscheidungsformen . . . . . . . . . . . . . . . . . . . . . . 1478

6. Klagerücknahme/Erledigung der Hauptsache . . . . . . . . . . . . . . . . . 1480

VI. Vorläufiger Rechtsschutz . . . . . . . . . . . . . . . . . . . . . . . . . . 1480

1. Zweigleisigkeit des vorläufigen Rechtsschutzes . . . . . . . . . . . . . . . . . 1481

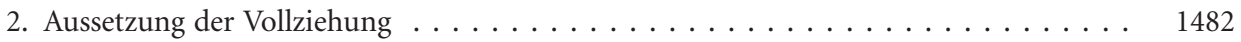

3. Einstweilige Anordnung $(\$ 114 \mathrm{FGO}) \ldots \ldots \ldots \ldots \ldots \ldots \ldots$

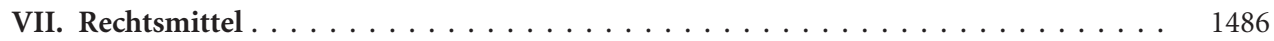

1. Überblick über das Rechtsmittelsystem . . . . . . . . . . . . . . . . . . . . . 1487

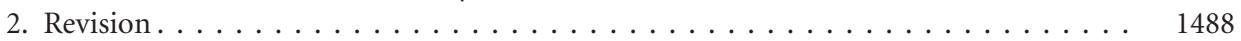

2.1 Zweck der Revision . . . . . . . . . . . . . . . . . . . . . . . . . 1488

2.2 Statthaftigkeit der Revision $(\$ 115$ I, II FGO) $\ldots \ldots \ldots \ldots \ldots \ldots \ldots \ldots \ldots$

2.3 Revisionszulassungsgründe $(\$ 115$ II FGO $) \ldots \ldots \ldots \ldots \ldots \ldots \ldots$

2.4 Grundsatz der Vollrevision . . . . . . . . . . . . . . . . . . . . . . . . . . 1491

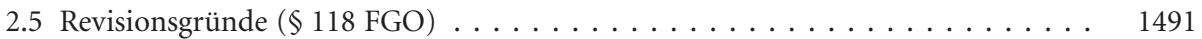

2.6 Revisionsverfahren . . . . . . . . . . . . . . . . . . . . . . . . . . . 1492

2.7 Entscheidung des Bundesfinanzhofs . . . . . . . . . . . . . . . . . . 1492

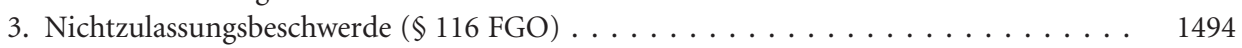

4. Beschwerde $(\$ 128 \mathrm{FGO}) \ldots \ldots \ldots \ldots \ldots \ldots \ldots \ldots \ldots$

VIII. Anhörungsrüge $(\$ 133$ a FGO $) \ldots \ldots \ldots \ldots \ldots \ldots \ldots \ldots \ldots \ldots$

IX. Kosten des Gerichtsverfahrens . . . . . . . . . . . . . . . . . . . . . . . . . 1496

X. Rechtskraft $(\$ 110$ FGO $) \ldots \ldots \ldots \ldots \ldots$. . . . . . . . . . . . . . . 1498

D. Verfassungsrechtlicher Rechtsschutz . . . . . . . . . . . . . . . . . . 1498

I. Verfassungsbeschwerde (Art. 93 I Nr. 4a GG) . . . . . . . . . . . . . . . . . 1499 


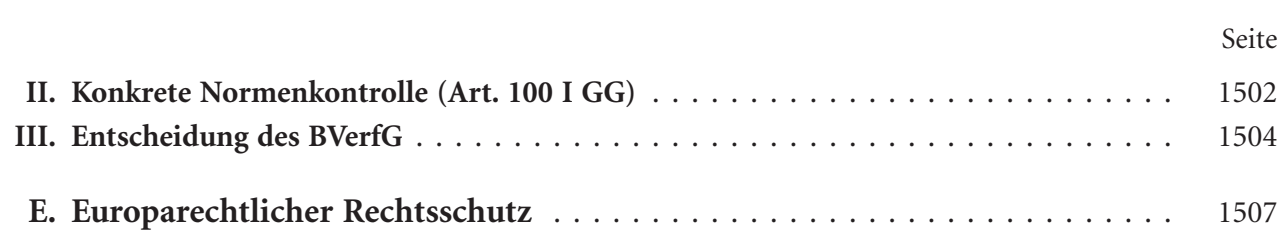

\section{$\$ 23$ Materielles Steuerstraf- und -ordnungswidrigkeitenrecht}

A. Überblick über das System des Steuerstraf- und -ordnungswidrigkeitenrechts .

I. Rechtfertigung eines Steuerstraf- und -ordnungswidrigkeitenrechts . . . . . . . . 1513

II. Unterscheidung zwischen Steuerverfehlungen und allgemeinen Straftaten und Ordnungswidrigkeiten .

III. Unterscheidung zwischen Steuerstraftaten und Steuerordnungswidrigkeiten . . . 1516

B. Die einzelnen Steuerstraftaten $\ldots \ldots \ldots \ldots \ldots \ldots \ldots \ldots$

I. Steuerhinterziehung $(\$ 370$ AO $) \ldots \ldots \ldots \ldots \ldots \ldots \ldots \ldots \ldots$

1. Geschütztes Rechtsgut und Deliktscharakter . . . . . . . . . . . . . 1518

2. Objektiver Tatbestand . . . . . . . . . . . . . . . . . . . . . 1519

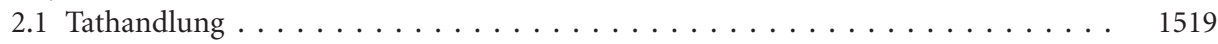

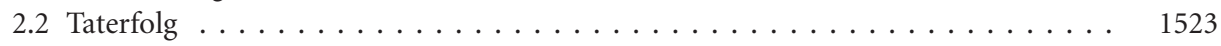

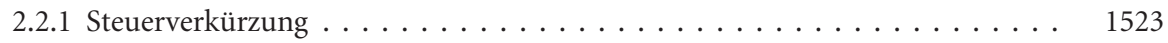

2.2.2 Erlangung eines nicht gerechtfertigten Steuervorteils . . . . . . . . . . . . . . . . . . 1525

2.2.3 Kompensationsverbot $(\$ 370$ IV 3 AO $) \ldots \ldots \ldots \ldots \ldots \ldots \ldots \ldots$

2.3 Kausalität zwischen Tathandlung und Taterfolg . . . . . . . . . . . . . . . 1527

2.4 Verkürzung von harmonisierten EU-Abgaben . . . . . . . . . . . . . . . . . 1528

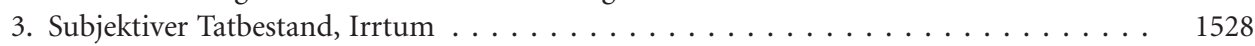

4. Zeitliche Stadien $\operatorname{der}$ Tat . . . . . . . . . . . . . . . . . . . . . . 1530

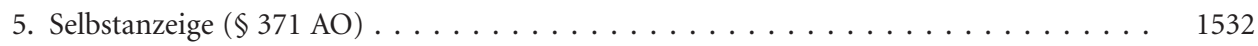

5.1 Rechtsnatur und Zweck der Selbstanzeige . . . . . . . . . . . . . . . . . . . . . . . 1532

5.2 Positive Strafbefreiungsvoraussetzungen $(\$ 371$ I, III AO $) \ldots \ldots \ldots \ldots \ldots \ldots . \ldots 1533$

5.3 Negative Strafbefreiungsvoraussetzungen $(\$ 371$ II AO $) \ldots \ldots \ldots \ldots \ldots \ldots \ldots$

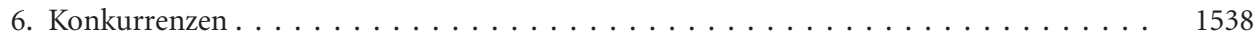

7. Strafzumessung . . . . . . . . . . . . . . . . . . . . . . . 1539

II. Gewerbs-/Bandenmäßige Schädigung des Umsatzsteueraufkommens (\$ 26c UStG) . 1544

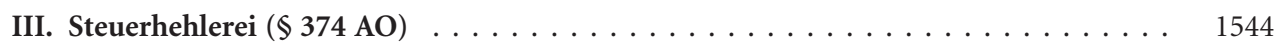

C. Die einzelnen Steuerordnungswidrigkeiten . . . . . . . . . . . . . . . 1544

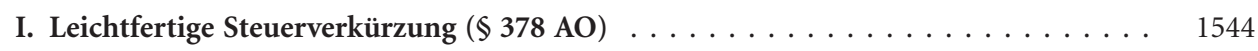

II. Schädigung des Umsatzsteueraufkommens $(\$ 26 \mathrm{~b}$ UStG) $\ldots \ldots \ldots \ldots \ldots \ldots$

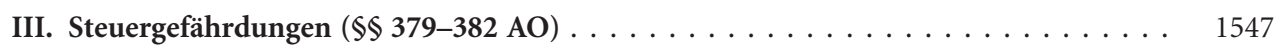

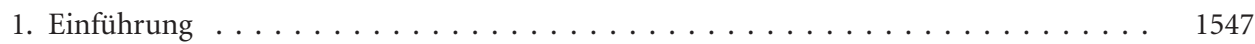

2. Allgemeine Steuergefährdung $(\$ 379 \mathrm{AO}) \ldots \ldots \ldots \ldots \ldots \ldots \ldots \ldots$

3. Gefährdung von Abzugsteuern $(\$ 380 \mathrm{AO}) \ldots \ldots \ldots \ldots \ldots \ldots \ldots$ 
4. Gefährdung von Verbrauchsteuern $(\$ 381 \mathrm{AO}) \ldots \ldots \ldots \ldots \ldots$. . . . . . . . . . 1549

5. Gefährdung von Ein- und Ausfuhrabgaben $(\$ 382$ AO) $\ldots \ldots \ldots \ldots \ldots$

IV. Unzulässiger Erwerb von Steuererstattungs- und Vergütungsansprüchen

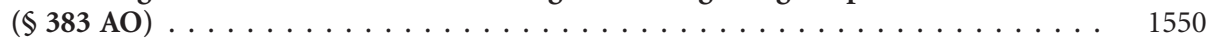

V. Zweckwidrige Verwendung des Identifikationsmerkmals des $\$ 139 \mathrm{a} A \mathrm{AO}$

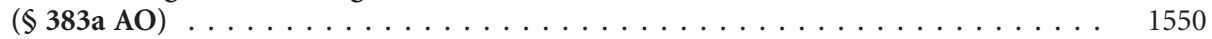

VI. Pflichtverletzung bei Übermittlung von Vollmachtsdaten $(\$ 383 b$ AO) $\ldots \ldots \ldots \ldots$

VII. Verletzung der Aufsichtspflicht in Betrieben und Unternehmen ( $\$ 130$ OWiG) . . . 1551

\section{\$24 Steuerstraf- und Steuerordnungswidrigkeitenverfahren}

A. Steuerstrafverfahren . . . . . . . . . . . . . . . . . 1553

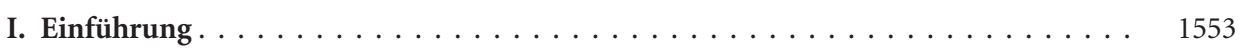

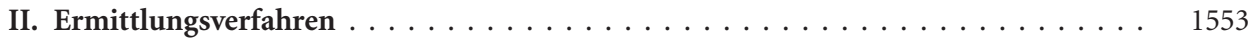

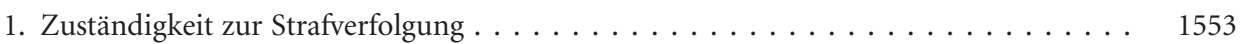

2. Einleitung des Ermittlungsverfahrens . . . . . . . . . . . . . . . . . . 1555

3. Befugnisse der Strafverfolgungsbehörden . . . . . . . . . . . . . . . . . . . . 1559

4. Rechtsstellung des Beschuldigten im Ermittlungsverfahren . . . . . . . . . . . . . . 1564

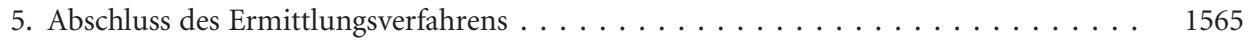

5.1 Strafbefehlsantrag, öffentliche Anklage . . . . . . . . . . . . . . . . 1565

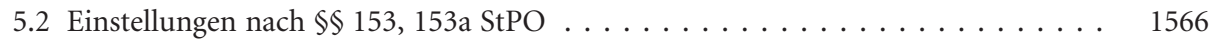

5.3 Absehen von der Strafverfolgung nach $\$ 398 \mathrm{a}$ AO . . . . . . . . . . . . . . . . 1567

5.4 Verständigungen im Ermittlungsverfahren . . . . . . . . . . . . . . . . . . 1568

III. Verfahren vor den Strafgerichten in Steuersachen . . . . . . . . . . . . . . . . . . . . 1569

1. Zuständiges Strafgericht . . . . . . . . . . . . . . . . . . . . . . . . . 1569

2. Öffentliche Klage vor den Strafgerichten . . . . . . . . . . . . . . . . . . . . . 1569

2.1 Strafbefehlsverfahren $(\$ \$ 407 \mathrm{ff} . \mathrm{StPO}) \ldots \ldots \ldots \ldots \ldots \ldots$

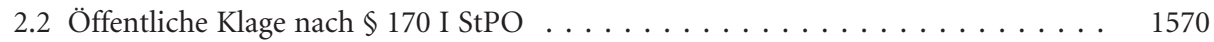

B. Steuerordnungswidrigkeitenverfahren $\ldots \ldots \ldots \ldots \ldots \ldots \ldots 15 \ldots \ldots \ldots$

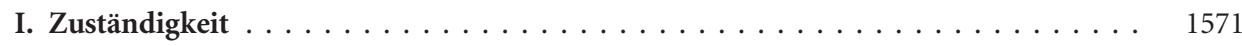

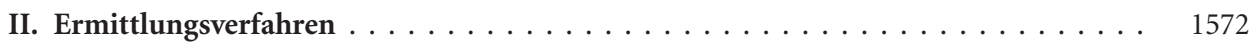

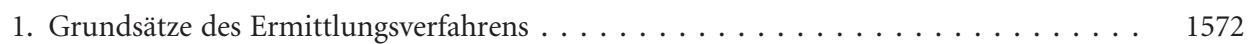

2. Abschluss des Ermittlungsverfahrens . . . . . . . . . . . . . . . . . 1572

III. Rechtsbehelf des Betroffenen . . . . . . . . . . . . . . . . . . . . . . 1572

Stichwortverzeichnis . . . . . . . . . . . . . . . . . . . . . . 1575 